\title{
A mRNA landscape of bovine embryos after standard and MAPK-inhibited culture conditions: a comparative analysis
}

Bas Brinkhof ${ }^{1}$, Helena TA van Tol', Marian JA Groot Koerkamp², Frank M Riemers ${ }^{3}$, Sascha G IJzer', Kaveh Mashayekhi ${ }^{1,4}$, Henk P Haagsman ${ }^{5}$ and Bernard AJ Roelen ${ }^{1 *}$

\begin{abstract}
Background: Genes and signalling pathways involved in pluripotency have been studied extensively in mouse and human pre-implantation embryos and embryonic stem (ES) cells. The unsuccessful attempts to generate ES cell lines from other species including cattle suggests that other genes and pathways are involved in maintaining pluripotency in these species. To investigate which genes are involved in bovine pluripotency, expression profiles were generated from morula, blastocyst, trophectoderm and inner cell mass (ICM) samples using microarray analysis. As MAPK inhibition can increase the NANOG/GATA6 ratio in the inner cell mass, additionally blastocysts were cultured in the presence of a MAPK inhibitor and changes in gene expression in the inner cell mass were analysed.

Results: Between morula and blastocyst 3,774 genes were differentially expressed and the largest differences were found in blastocyst up-regulated genes. Gene ontology (GO) analysis shows lipid metabolic process as the term most enriched with genes expressed at higher levels in blastocysts. Genes with higher expression levels in morulae were enriched in the RNA processing $\mathrm{GO}$ term. Of the 497 differentially expressed genes comparing ICM and TE, the expression of NANOG, SOX2 and POU5F1 was increased in the ICM confirming their evolutionary preserved role in pluripotency. Several genes implicated to be involved in differentiation or fate determination were also expressed at higher levels in the ICM. Genes expressed at higher levels in the ICM were enriched in the RNA splicing and regulation of gene expression GO term. Although NANOG expression was elevated upon MAPK inhibition, SOX2 and POU5F1 expression showed little increase. Expression of other genes in the MAPK pathway including DUSP4 and SPRY4, or influenced by MAPK inhibition such as IFNT, was down-regulated.
\end{abstract}

Conclusion: The data obtained from the microarray studies provide further insight in gene expression during bovine embryonic development. They show an expression profile in pluripotent cells that indicates a pluripotent, epiblast-like state. The inability to culture ICM cells as stem cells in the presence of an inhibitor of MAPK activity together with the reported data indicates that MAPK inhibition alone is not sufficient to maintain a pluripotent character in bovine cells.

Keywords: Pluripotency, Cattle, Morula, Blastocyst, ICM, Trophectoderm, NANOG, MAPK

\footnotetext{
*Correspondence: B.A.J.Roelen@uu.nl

${ }^{1}$ Department of Farm Animal Health, Faculty of Veterinary Medicine, Utrecht University, Yalelaan 104, Utrecht 3584 CM, The Netherlands

Full list of author information is available at the end of the article
} 


\section{Background}

In mammals, early life starts with the formation of a zygote as a result of the fertilization of an oocyte. Sequential cleavage divisions lead to the formation of a morula stage embryo wherein a fluid-filled cavity emerges called the blastocoel. Two differentiated groups of cells can be distinguished in the embryo that is now called a blastocyst. A group of cells adjacent to the blastocoel, the inner cell mass (ICM), is able to contribute to all cells of the three germ layers and is therefore referred to as being pluripotent. The other group of cells, called the trophectoderm (TE), forms an epithelium surrounding the blastocoel and the ICM and is important for implantation within the uterus and contributes to the non-maternal part of the placenta. In the ICM further differentiation occurs by the formation of the epiblast, that will form the foetus, and the formation of extra-embryonic primitive endoderm $(\mathrm{PE})$ contributing to the yolk sac.

Studies with mouse embryos have advanced our understanding of how a pluripotent cell population is established during pre-implantation development [1-4]. During the first differentiation, the transcription factors CDX2 and OCT4 are key regulators for the formation of respectively $\mathrm{TE}$ and ICM. CDX2 represses the activity of OCT4 in mouse TE [5] and is virtually absent in ICM cells [6]. OCT4 in turn can counteract CDX2 activity in the inner cells of the morula. The second differentiation is indicated by the expression of either NANOG or GATA6 in ICM cells fated to become the epiblast or PE respectively [7]. Like for CDX2 and OCT4 in the morula, NANOG and GATA6 inhibit each other's transcription [4]. Whether the same genes and signalling pathways are also involved in the formation of a pluripotent cell population in other mammals remains to be established. Indeed, in contrast to the mouse, OCT4 protein remains present in the TE of bovine blastocysts even after transcription is down-regulated [8] and its expression is not negatively regulated by CDX2 [9]. In mouse embryos it has been established that GATA6-stimulated fibroblast growth factor (FGF) signalling via the extracellular signal-regulated protein kinase (ERK) is responsible for NANOG repression and thereby the formation of primitive endoderm [2,10-12]. In bovine and human embryos however, although GATA6 expression is specific for primitive endoderm, inhibition of ERK signalling had a more moderate (bovine) or no (human) effect on the numbers of NANOG and GATA6 expressing cells suggesting that in these species other pathways are involved in the formation of the pluripotent cell population [13-15]. These findings suggest speciesspecific mechanisms active in the specification of ICM, $\mathrm{TE}$, epiblast and PE lineages and that further insight is needed into the molecular basis of cell sorting during the two first differentiation events.

When mouse ICM cells are cultured under defined conditions, their pluripotent character can be maintained $[16,17]$. However, the establishment of such embryonic stem (ES) cells has only been successful for mice, non-human primates [18], humans [19] and rats [20]. Although pluripotency refers to the capacity to give rise to all embryonic and adult cell types, including the germ line, various states of pluripotency have been described. These states are referred to as "naïve" and "primed", with "primed" being more developmentally restricted [21]. In mammals other than primates and rodents, the correct stages of embryos that contain pluripotent cells and culture conditions that maintain pluripotency have yet to be established [22].

In order to identify genes that may be important for the acquisition and maintenance of pluripotency in bovine embryos a genome-wide gene expression analysis was performed in morulae, intact blastocysts, TE and ICM. Analyses of gene expression patterns in pre-implantation embryos to distinguish between pluripotent cells of the ICM versus those of the TE have previously made use of cell lines because of the technical difficulties of separating ICM from TE $[23,24]$. Here we have manually dissected individual ICMs from TE. As the late ICM is composed of both pluripotent epiblast cells and the PE, the pluripotent character of the ICM was enhanced by inhibition of the ERK-pathway resulting in an increased percentage of ICM cells that express NANOG.

\section{Results}

\section{Gene expression profile of pre-implantation embryos}

To identify genes involved in bovine pluripotency, gene expression profiles of morula and blastocyst embryos, ICM and TE were generated using microarray analysis. Bovine cumulus oocyte complexes (COCs) were in vitro matured, fertilized and cultured for 5 or 9 days to obtain morula and blastocyst stage embryos, respectively (Figure 1A,B). In addition, ICM and TE were manually dissected from day 9 blastocysts (Figure 1C,D). From all samples RNA was isolated and only those with a RNA integrity number $(\mathrm{RIN}) \geq 8.0$ were used for further analysis. To compensate for biological and technical errors, two biological replicates of each sample were labelled with either Cy3 or Cy5 and hybridized on the arrays with a common reference pool consisting of blastocysts so all samples could be compared (Figure 1E).

Samples were hybridized on a microarray slide containing almost 44,000 probes per array coding for 14,000 gene transcripts indicating that for a subset of genes more than one probe was present. If the position of the probe is nearer to the 3' end of the corresponding gene, signal intensity is expected to be higher [25] and chance of incorrect signal by variations in RNA integrity is smaller [26]. Therefore, the expression of the probes corresponding to the most 3' ends of genes was used for the analysis $[27,28]$. Gene expression levels in morula, blastocyst, ICM and TE were determined and a hierarchical clustering analysis was performed. The 

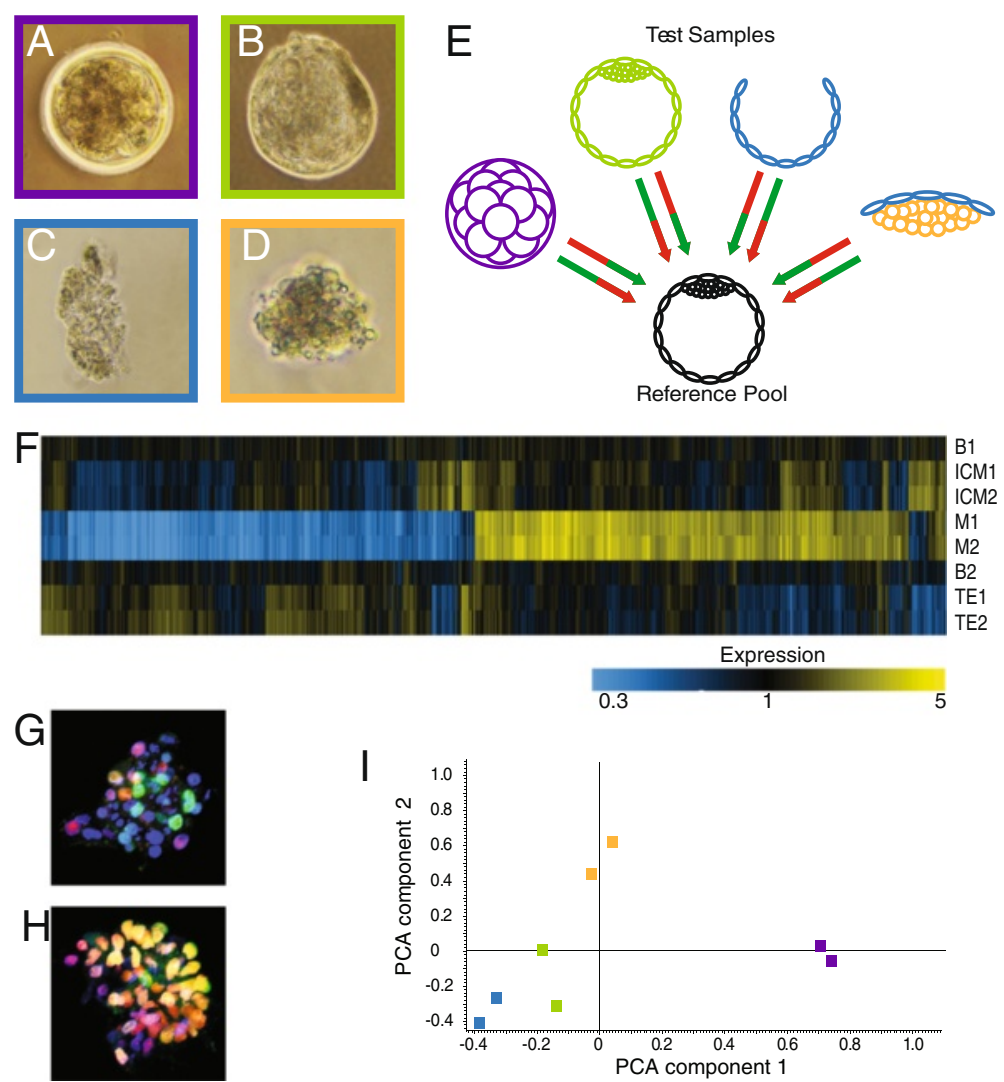

Figure 1 Microarray set-up and sample validation. RNA from morula (A, purple), blastocyst (B, green), trophectoderm (C, blue) and inner cell mass ( $\mathbf{D}$, orange) was hybridized on microarrays. A common reference sample composed of blastocysts was hybridized with each sample in duplicate in balanced dye-swap (E, arrows indicate an array and the used fluorescent label; Cy3: green; Cy5: red). The heat map (F) illustrates pairwise clustering of microarray sample replicates. Yellow colour represents over-expressed probes and blue colour represents under-expressed probes as indicated by the colour legend ( $B$ = blastocyst; ICM = inner cell mass; $M=$ morula; TE = trophectoderm). Representative pictures of immunofluorescent labelling of dissected ICM (G) and TE (H) for GATA6 (green) and CDX2 (red); double GATA6-CDX2 nuclei appear yellow. Nuclear staining by DAPI (blue). A 2D principal component analysis plot (I) with sample position indicating clustering of trophectoderm (blue), blastocyst (green), inner cell mass (orange) and morula (purple) replicates.

constructed heat map shows clear pairing of the morula, ICM and TE samples (Figure 1F). This is particularly important for the TE and ICM samples since these were manually dissected and confirms the reproducibility of the dissection. We used mechanical isolation of ICM from TE using tungsten needles. A selection of isolated ICMs was stained for CDX2 and GATA6 to identify the contribution of TE cells to the pooled microarray samples. The isolated ICMs contained only $\sim 20 \%$ CDX2 positive TE (Figure 1G). Since however some TE cells remained attached to the ICM, throughout the manuscript "ICM" refers to the ICM containing few TE cells. In the TE samples all cells were CDX2 and GATA6 positive (Figure 1H). Blastocyst samples did not pair since their difference with the reference is minimal indicated by a near black appearance in the heat map. A principal component analysis (PCA) further identified four categories according to cell type or developmental stage. In a 2D plot, morula samples separate the farthest from the other samples. TE and ICM samples are clearly separated from each other with the blastocyst replicates in between (Figure 1I).

To further confirm the specificity of the samples, expression levels of genes that are known to be differentially expressed in bovine embryos were compared. Of the selected genes HMGB1, SOX2 and POUSF1 (coding for OCT4 protein) are known to be expressed at relatively high levels in bovine morula embryos [29-31], $C D X 2$ and KRT18 have the highest expression levels in TE [30,32] while FN1 and NANOG are abundantly expressed in the ICM [30]. The relative expression levels of the selected genes as determined by microarray analysis in morula, blastocyst, ICM and TE were as expected, with highest levels of HMGB1 and SOX2 expression in morulae, POU5F1 expression predominantly in morulae and ICM, highest FN1 and NANOG expression in the ICM and $C D X 2$ and KRT18 expression at highest levels in TE (Figure 2A). These selected genes and 

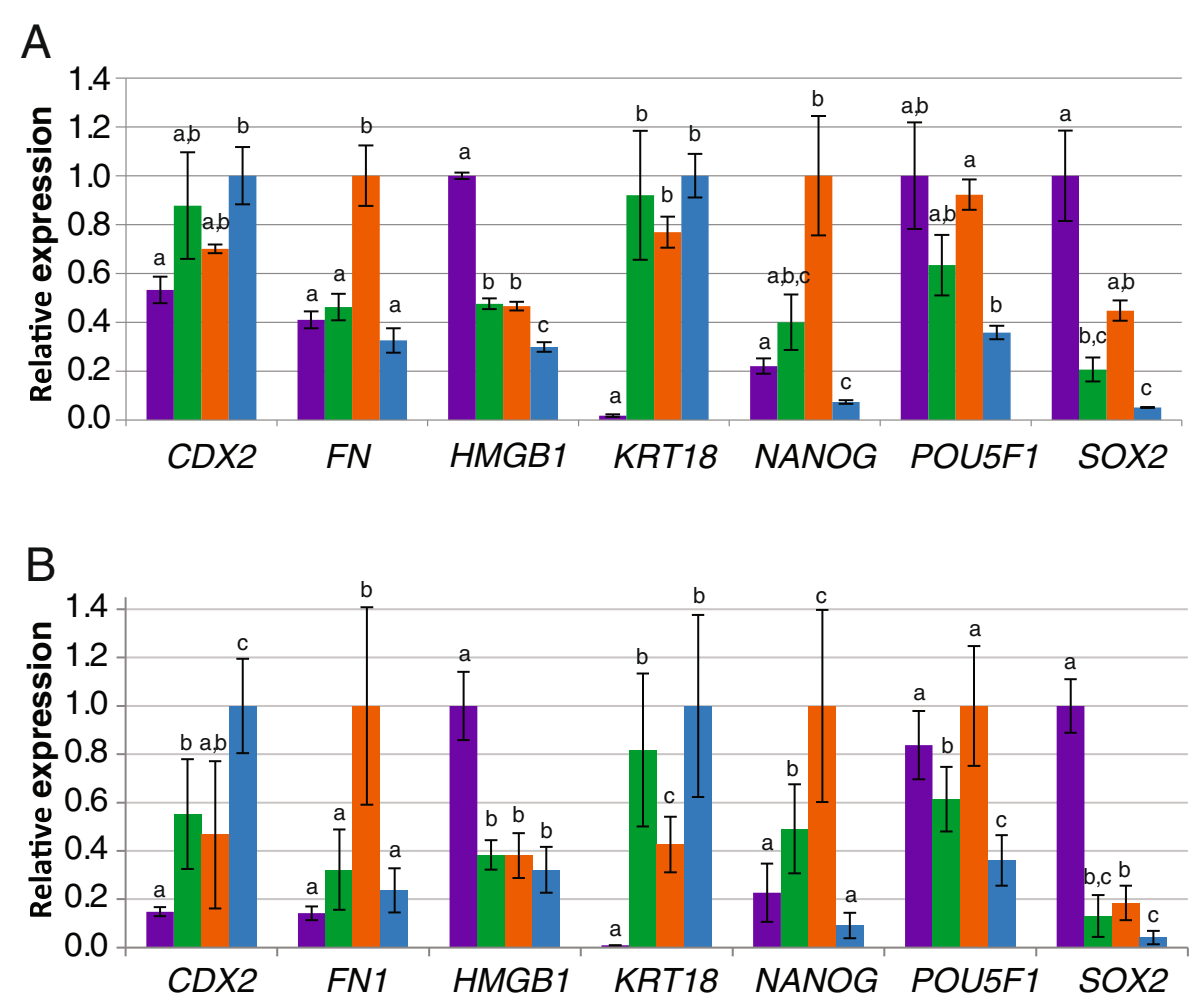

Figure 2 Relative gene expression. Microarray data were analysed for selected genes known for their expression in morula (purple), blastocyst (green), ICM (orange) and TE (blue) (A). The same genes were analysed by qRT-PCR in 4-6 samples per embryo stage or cell type revealing the same pattern (B). Normalization was performed with the reference genes encoding RPL15, SDHA and YWHAZ. Y-axis depicts relative mean expression to sample with highest expression set at 1 per gene. Bars with different letters are significantly different ( $p<0.05$ ) and error bars indicate standard deviation.

five additional genes (Additional file 1: Figure S1) were also analysed for their expression levels by qRT-PCR, revealing a similar expression profile validating sample identity and demonstrating that the microarray data accurately reflect relative expression levels (Figure 2B).

\section{Genes differentially expressed between morulae and blastocysts}

Most differences in gene expression were found between morulae and blastocysts. When gene expression in morulae was compared with that in blastocysts using a $>2$-fold difference with p-value $<0.05$ as cut-off, 3,774 genes were differentially expressed. In the blastocyst, 1,960 genes were up-regulated, up to 107 -fold, while 1,814 genes were expressed at higher levels in morulae (Figure 3A and Additional file 2: Table S1). The 25 most differentially expressed genes were expressed with at least a 30-fold difference of which only 1 gene (ETNPPL) was expressed at higher levels in the morula (Table 1).

To identify properties of the differentially expressed genes a Parametric Analysis of Gene Set Enrichment (PAGE) was performed using AgriGO [33] and a list of the five mostenriched gene ontology (GO) terms per categorie was generated (Table 2). A large group of differentially expressed genes was involved in the lipid metabolic process (GO:0006629) in the blastocyst. A much smaller group of genes that function in pepsin $A$ activity (GO:0004194) was over-represented in blastocysts and indeed, a large group of genes upregulated in the blastocyst located to the plasma membrane (GO:0005886). Compared to the blastocyst, in the morula more genes were involved in the nucleobasecontaining compound metabolic process (GO:0006139) and more specifically in RNA processing (GO:0006396). Morula up-regulated genes were found in the enriched molecular function GO terms nucleic acid binding (GO:0003676) and transcription regulator activity (GO:0030528).

\section{Genes differentially expressed between ICM and TE}

When gene expression in the ICM was compared with that of the TE, 497 genes were differentially expressed. Here, the majority (406) of the differentially expressed genes were expressed at higher levels in the ICM. Of all genes, the difference in expression levels of NANOG was the largest (13fold up-regulated in the ICM, Table 3 and Additional file 2: Table S2). SOX2 and POU5F1 that together with NANOG form the core transcriptional regulatory circuitry in pluripotent cells were also over-expressed in the ICM compared with TE (Figure 3B). 

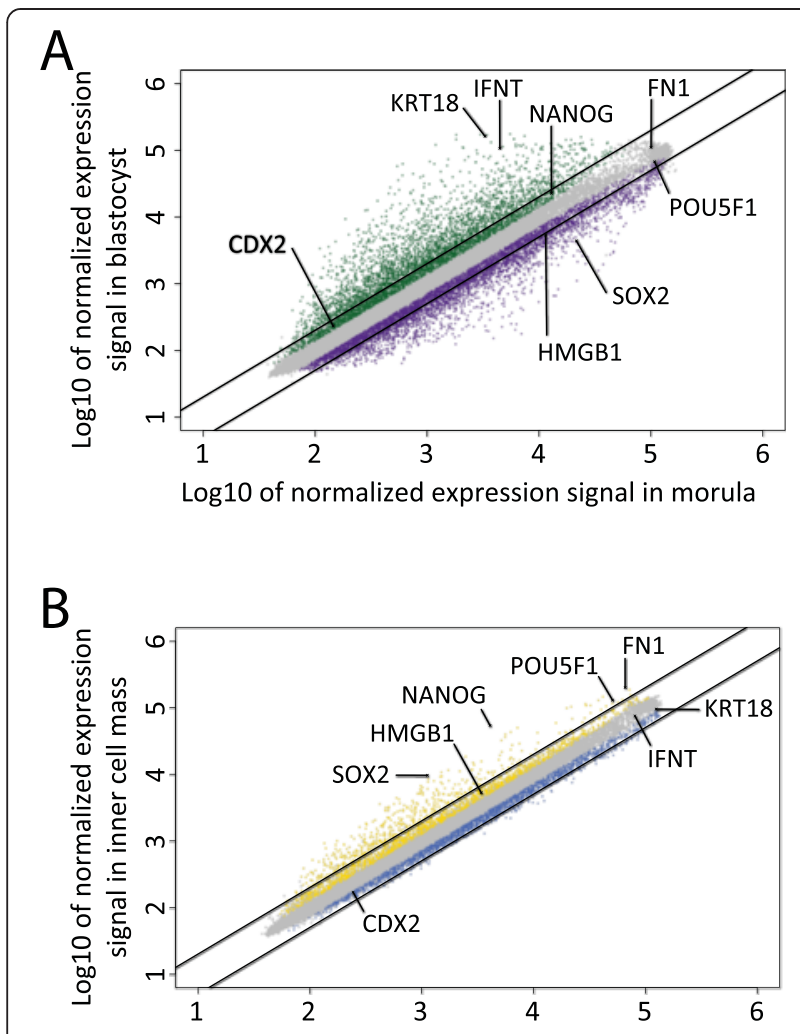

Log10 of normalized expression signal in trophectoderm

Figure 3 Relative gene expression in blastocyst versus morula and inner cell mass versus trophectoderm samples. All probes representing genes (grey) were plotted for their expression levels. Black lines represent the 2-fold cut off. Axes are Log10 transformed and depict the normalized expression signal in the indicated sample. Genes analysed in qRT-PCR are indicated. (A) Genes with significant $(p \leq 0.05)$ higher expression levels in blastocyst or morula are indicated with green or purple dots, respectively. (B) Genes with significant $(p \leq 0.05)$ higher expression levels in inner cell mass or trophectoderm are indicated with orange or blue dots, respectively.

For human ES cells, a network of NANOG-, SOX2and POU5F1-target genes that encode transcription factors and chromatin modulators has been established [34]. From the list of positively regulated genes in human ES cells, apart from the core network only expression of STAT3 and ZIC3 was significantly up-regulated in bovine ICM versus TE (Additional file 2: Table S2). Again, we performed a parametric analysis of gene set enrichment with the genes differentially expressed between ICM and TE in AgriGO [33]. With a false discovery rate $(\mathrm{FDR}) \leq 0.1$, enzyme linked receptor protein signaling pathway (GO:0007167) and peptidyl-tyrosine phosphorylation (GO:0018108) terms were enriched for the ICM whereas for the TE, genes were enriched in the sterol biosynthetic process (GO:0016126) (Table 4). Only genes up-regulated in respect to the TE were used for a singular enrichment analysis (SEA) in order to identify characteristics specific for the cells of the ICM (Additional file 2: Table S3). In particular, terms containing genes involved in RNA splicing (GO:0008380) and regulation of gene expression (GO:0010468) were enriched even to a more specific level of enriched child terms like nuclear mRNA splicing (GO:0000398) and chromatin silencing (GO:0006342), respectively (Figure 4, Additional file 2: Table S3 and Additional file 3: Figure S2).

\section{Genes differentially expressed between MAPK-inhibited and control ICMs}

It has been described that culture of ICM cells in the presence of an FGFR inhibitor, a MAPK inhibitor and an inhibitor of GSK3 3 , the so-called 3i culture system, leads to stable ES cell lines from non-permissive mouse strains $[10,35]$ and rat embryos [20]. Culture of mouse embryos in the presence of a MAPK inhibitor resulted in all cells of the ICM expressing Nanog while the expression of Gata6 was down-regulated [11]. Similarly, when bovine embryos were cultured in the presence of the MAPK inhibitor PD0325901, a larger percentage, although not all, of the ICM cells expressed NANOG [13]. Therefore, in order to identify NANOG target genes and genes that may be important for pluripotency, ICMs were isolated from bovine embryos cultured in the presence of the MAPK inhibitor PD0325901. Gene expression in these ICMs was compared with that from control ICMs using microarray analysis. In total 94 genes were differentially regulated between control (DMSO) and MAPK-inhibited ICMs, $\geq 2$-fold difference with p-value $\leq 0.05$ as cut-off, with the expression of 44 genes up-regulated and the expression of 50 genes down-regulated (Additional file 2: Table S4). As expected, NANOG expression was upregulated in the MAPK-inhibited ICM as detected by microarray analysis (Figure 5A,B). Expression differences between control ICM and ICM from embryos exposed to the MAPK inhibitor detected by qRT-PCR verified the microarray data (Figure 5B,C and Additional file 4: Figure S3). Furthermore, immunostaining showed an increase in the percentage of NANOG expressing cells in the ICM after MAPK inhibition (Additional file 5: Figure S4) as we had previously established [13]. To our surprise several interferon coding genes were dramatically down-regulated after MAPK inhibition such as IFNW1 and IFNT (Figure 5A). Gene expression analysis by qRTPCR confirmed the microarray results and further showed a decreased IFNT expression in TE and to a greater extend in ICM upon MAPK inhibition (Figure 5D).

Genes up-regulated in the PD-treated or in the control ICMs were enriched in 189 of the same GO terms after a singular enrichment analysis containing at least two genes and a FDR $\leq 0.1$ (Additional file 2: Table S5 and Figure 5E). When the relative gene expression was taken into account only $6 \mathrm{GO}$ terms were found to be enriched with a FDR $<0.1$, of which 4 were under-represented in 
Table 1 List of the most differentially expressed genes between blastocyst and morula

\begin{tabular}{|c|c|c|c|c|}
\hline Rank & Entrez Gene name & Gene discription & AgriGo ID & FC \\
\hline 1 & PLS1 & Plastin-1 & ENSBTAP00000053019 & 107.2 \\
\hline 2 & PAGE4 & $\mathrm{G}$ antigen family $\mathrm{C}$ member 1 & ENSBTAP00000047904 & 103.9 \\
\hline 3 & PGHS-2 & $\begin{array}{l}\text { prostaglandin-endoperoxide synthase } 2 \text { (prostaglandin } \\
\text { G/H synthase and cyclooxygenase) (PTGS2), mRNA. }\end{array}$ & ENSBTAP00000018774 & 94.1 \\
\hline 4 & ANXA3 & annexin A3 & ENSBTAP00000042843 & 70.5 \\
\hline 5 & ALDH1A3 & aldehyde dehydrogenase 1 family, member $\mathrm{A} 3$ & ENSBTAP00000012030 & 64.9 \\
\hline 6 & SEPP1 & selenoprotein P, plasma, 1 (SEPP1), mRNA & NP_776884 & 57.8 \\
\hline 7 & GCA & grancalcin, EF-hand calcium binding protein & ENSBTAP00000024550 & 54.1 \\
\hline 8 & MYOF & myoferlin & ENSBTAP00000038769 & 52.0 \\
\hline 9 & KRT8 & keratin, type II cytoskeletal 8 & ENSBTAP00000001108 & 51.9 \\
\hline 10 & KRT18 & KRT18 proteinUncharacterized protein & ENSBTAP00000001988 & 49.2 \\
\hline 11 & SLC23A1 & solute carrier family 23 (ascorbic acid transporter), member 1 & ENSBTAP00000010823 & 48.7 \\
\hline 12 & ZFP37 & Uncharacterized protein & ENSBTAP00000024598 & 45.6 \\
\hline 13 & PRSS22 & Uncharacterized protein & ENSBTAP00000021967 & 43.2 \\
\hline 14 & AGRN & agrin & ENSBTAP00000017563 & 39.4 \\
\hline 15 & ETNPPL & Bos taurus alanine-glyoxylate aminotransferase 2-like 1 (AGXT2L1), mRNA. & ENSBTAP00000013587 & -38.8 \\
\hline 16 & CYP51A1 & Lanosterol 14-alpha demethylase & ENSBTAP00000002582 & 36.3 \\
\hline 17 & LDLR & low-density lipoprotein receptor & ENSBTAP00000016342 & 34.4 \\
\hline 18 & CNN2 & Calponin-2 & ENSBTAP00000027670 & 33.8 \\
\hline 19 & LOC787705 & Uncharacterized protein & & 33.7 \\
\hline 20 & HMOX1 & Heme oxygenase 1 & ENSBTAP00000020701 & 33.2 \\
\hline 21 & PLAU & $\begin{array}{l}\text { Urokinase-type plasminogen activatorUrokinase-type plasminogen } \\
\text { activator long chain AUrokinase-type plasminogen activator short } \\
\text { chain AUrokinase-type plasminogen activator chain B }\end{array}$ & ENSBTAP00000007806 & 32.9 \\
\hline 22 & PQLC3 & PQ-loop repeat-containing protein 3 & ENSBTAP00000027051 & 31.6 \\
\hline 23 & PDZK1 & $\mathrm{Na}(+) / \mathrm{H}(+)$ exchange regulatory cofactor NHE-RF3 & ENSBTAP00000007638 & 31.0 \\
\hline 24 & LOC523509 & Uncharacterized protein & ENSBTAP00000050990 & 30.9 \\
\hline 25 & TMEM20 & Bos taurus solute carrier family 35, member G1 (SLC35G1), mRNA. & ENSBTAP000000045606 & 30.0 \\
\hline
\end{tabular}

The 25 most differentially expressed genes ( $\geq 30$-fold; $\mathrm{p} \leq 0.05$ ) between blastocyst and morula are listed. $\mathrm{FC}=$ fold-change and positive values indicate higher expression in blastocyst and negative values have higher expression in morula.

the PD-treated ICMs (Table 5). The only functiondescribing term was receptor binding (GO:0005102) and this term was under-represented in the PD group.

\section{Cross-comparisons}

The 497 genes differentially expressed in the ICM versus TE and the 95 differentially expressed genes in the MAPK inhibited versus control ICMs were compared revealing that 42 genes were shared (Table 6). Of these genes 15 were both up-regulated in ICM and after MAPK inhibition while 27 were contra-regulated (Figure 6A). Only PRPH was expressed at lower levels in ICM than in TE and 26 genes were down-regulated after MAPK inhibition and the expression of 16 genes was further up-regulated (Table 6). Although it has been described that NANOG activates POU5F1 and SOX2 transcription, expression of these genes was not significantly altered after up-regulation of NANOG expression by MAPK inhibition.

The expression of GATA6 was significantly downregulated in the ICM after MAPK inhibition, although the difference was less than 2-fold and was not significant in the qRT-PCR analysis. The expression of 26 other ICMspecific genes was significantly down-regulated upon MAPK inhibition suggesting that these genes are involved in primitive endoderm formation (Figure 5 and Table 6). Expression of a number of the genes was also analysed by qRT-PCR showing a similar pattern and validating the microarray data (Figure 5 and Additional file 4: Figure S3). Indeed mouse follistatin, coded by Fst, has been implicated as a marker for primitive endoderm derivatives [36]. Other genes down-regulated in the MAPK inhibited bovine ICMs themselves code for negative regulators of MAPK activity such as DUSP4 and SPRY4. 
Table 2 AgriGo parametric analysis of gene set enrichment (PAGE) analysis (blastocyst versus morula)

\begin{tabular}{|c|c|c|c|c|c|}
\hline GO_acc & Ontology & Description & Genes \# & p-value & FDR \\
\hline GO:0006629 & $P$ & lipid metabolic process & 311 & 0 & 0 \\
\hline GO:0016070 & $P$ & RNA metabolic process & 840 & $2.70 \mathrm{E}-29$ & $2.70 E-26$ \\
\hline GO:0006396 & $P$ & RNA processing & 242 & $1.00 \mathrm{E}-28$ & 7.00E-26 \\
\hline GO:0010467 & $P$ & gene expression & 1068 & $6.50 \mathrm{E}-22$ & 3.20E-19 \\
\hline GO:0006139 & P & $\begin{array}{l}\text { nucleobase, nucleoside, nucleotide and } \\
\text { nucleic acid metabolic process }\end{array}$ & 1169 & 4.20E-20 & 1.70E-17 \\
\hline GO:0003676 & F & nucleic acid binding & 929 & $5.70 \mathrm{E}-35$ & 2.40E-32 \\
\hline GO:0003723 & $\mathrm{F}$ & RNA binding & 252 & $1.00 \mathrm{E}-20$ & 2.20E-18 \\
\hline GO:0003677 & F & DNA binding & 623 & 7.00E-19 & $1.00 \mathrm{E}-16$ \\
\hline GO:0030528 & $\mathrm{F}$ & transcription regulator activity & 445 & $4.40 \mathrm{E}-11$ & 4.70E-09 \\
\hline GO:0004194 & $\mathrm{F}$ & pepsin A activity & 14 & $1.40 \mathrm{E}-10$ & $1.20 \mathrm{E}-08$ \\
\hline GO:0016020 & C & membrane & 1629 & 0 & 0 \\
\hline GO:0005886 & C & plasma membrane & 907 & 0 & 0 \\
\hline GO:0044425 & C & membrane part & 1280 & 0 & 0 \\
\hline GO:0044421 & C & extracellular region part & 564 & 0 & 0 \\
\hline GO:0016021 & C & integral to membrane & 1012 & 0 & 0 \\
\hline
\end{tabular}

Genes differentially expressed between blastocyst and morula were assessed for their properties described by gene ontology (GO) terms in respect to their relative expression. The five most significantly enriched GO-terms (according to $p$-value) are listed for each $\mathrm{GO}$ domain. $\mathrm{P}=\mathrm{Biological}$ Process, $\mathrm{F}=\mathrm{Molecular}$ Function and $\mathrm{C}=$ Cellular Component. Bold descriptions indicate enrichment for blastocyst. Regular descriptions indicate enrichment for morula. FDR $=$ False Discovery Rate (Hochberg).

The 42 shared genes were analyzed for their properties by gene ontology analysis. A PAGE analysis in AgriGO revealed 59 enriched GO-terms of which none had a FDR $<$ 0.1 . When the SEA was performed using either ICM upregulated, PD up-regulated or PD down-regulated genes (Additional file 2: Table S6), a Venn diagram with the enriched terms $(F D R<0.1)$ revealed 34 enriched GOterms shared between the up-regulated gene comparisons (Figure 6B, Additional file 2: Table S6).

\section{Discussion}

During bovine pre-implantation development several cell types display a pluripotent character. The failure in generating true pluripotent ES cell lines from Bos taurus embryos however indicates that, compared with murine and human embryos, other genes are involved in maintenance of pluripotency, that the correct embryonic stage with pluripotent cells has not been used, or that the culture conditions employed did not sufficiently inhibit differentiation. Interestingly, induced pluripotent stem (iPS) cells generated from bovine cells also behave differently than mouse iPS cells. Similar to porcine iPS cells, the introduced transgenes are not silenced in the currently used culture conditions but remain expressed in these cells suggesting that other factors are needed for maintenance of pluripotency [37]. We performed a microarray analysis comparing morula, blastocyst, ICM and TE gene expression profiles to identify genes possibly involved in pluripotency. Further enrichment of the pluripotent character of the ICM was achieved by inhibiting the MAPK pathway through exposure to the MEK inhibitor PD0325901 during in vitro culture thereby increasing the percentage of NANOG expressing cells in the ICM/epiblast $[13,14]$.

To obtain samples for the microarray analysis embryos were cultured up to the morula stage or blastocyst stage. Blastocysts were dissected manually to separate ICM and TE. The advantage of this technique is that ICM and $\mathrm{TE}$ are isolated from the same embryo, in contrast to for example a technique like immunosurgery. Manually dissecting blastocysts is challenging however and it is unavoidable that few TE cells remain attached to the ICM. We therefore verified that the separation of the two cell types was successful. For separation of ICM from TE, Nagatomo et al. have used either a micromanipulator or mild trypsin treatment to separate ICM [38]. ICMs isolated using the micromanipulator still contained $43.3 \%$ TE cells [38]. In our hands the percentage of TE cells remaining in the ICM isolates was $\sim 20 \%$ as determined by CDX2 expression, indicating a low contribution of TE cells to the ICM transcriptome. The disadvantage of mild trypsin treatment to isolate 'pure' ICM cells, is that TE and ICM cannot be compared from the same embryo and that the trypsin treatment by itself may cause a difference in gene expression. The observation that duplicate samples paired together and that TE and ICM clustered apart from each other together with the expected expression patterns of known TE- and ICM-specific genes in the microarray as 
Table 3 List of the most differentially expressed genes between inner cell mass and trophectoderm

\begin{tabular}{|c|c|c|c|c|}
\hline Rank & Entrez gene name & Gene description & AgriGo ID & FC \\
\hline 1 & NANOG & Homeobox protein NANOG & ENSBTAP00000027863 & 13.2 \\
\hline 2 & UPP1 & uridine phosphorylase 1 & ENSBTAP00000011088 & 8.9 \\
\hline 3 & SOX2 & SRY (sex determining region Y)-box 2 & ENSBTAP00000015411 & 8.6 \\
\hline 4 & CAV1 & Caveolin-1 & ENSBTAP00000023751 & 7.8 \\
\hline 5 & AK3L1 & Adenylate kinase isoenzyme 4, mitochondrial & Q0VCP1 & 7.5 \\
\hline 6 & LOC616039 & pancreatic trypsin inhibitor-like & XP_873093 & 7.4 \\
\hline 7 & OTX2 & agilent:"Bos taurus orthodenticle homeobox 2 (OTX2), mRNA & ENSBTAP00000019616 & 7.2 \\
\hline 8 & GPC4 & agilent:"Bos taurus glypican 4 (GPC4), mRNA & ENSBTAP00000027510 & 7.1 \\
\hline 9 & HAS2 & hyaluronan synthase 2 & ENSBTAP00000026503 & 7.1 \\
\hline 10 & SLC4A7 & solute carrier family 4, sodium bicarbonate cotransporter, member 7 & AAl42306.1 & 7.1 \\
\hline 11 & HNF4A & agilent:"Bos taurus hepatocyte nuclear factor 4, alpha (HNF4A), mRNA & ENSBTAP00000016078 & 7.0 \\
\hline 12 & CLIC6 & CLIC6 chloride intracellular channel 6 & ENSBTAP00000002299 & 6.9 \\
\hline 13 & LGALS4 & galectin-4 & ENSBTAP00000021701 & 6.8 \\
\hline 14 & ID1 & DNA-binding protein inhibitor ID-1 & ENSBTAP00000021521 & 6.7 \\
\hline 15 & FLRT3 & fibronectin leucine rich transmembrane protein 3 & ENSBTAP00000004298 & 6.6 \\
\hline 16 & PDGFRA & $\begin{array}{l}\text { agilent:"Bos taurus platelet-derived growth factor receptor, alpha } \\
\text { polypeptide (PDGFRA), mRNA }\end{array}$ & ENSBTAP00000009441 & 6.6 \\
\hline 17 & NID1 & nidogen 1 & ENSBTAP00000009531 & 6.5 \\
\hline 18 & KIT & Mast/stem cell growth factor receptor & ENSBTAP00000003498 & 6.5 \\
\hline 19 & GRP & agilent:"Bos taurus gastrin-releasing peptide GRP mRNA, complete cds. & ENSBTAP00000006297 & 6.5 \\
\hline 20 & LOC100139916 & LOC100139916 interleukin 32-like & & 6.5 \\
\hline 21 & TKTL1 & Transketolase-like protein 1 & ENSBTAP00000036249 & 6.4 \\
\hline 22 & $\mathrm{~A} 2 \mathrm{M}$ & Alpha-2-macroglobulin & ENSBTAP00000006167 & 6.4 \\
\hline 23 & PDYN & proenkephalin-B preproprotein & AAI51344.1 & 6.1 \\
\hline 24 & ACTG2 & actin, gamma 2, smooth muscle, enteric & ENSBTAP00000036954 & 6.0 \\
\hline 25 & MME & membrane metallo-endopeptidase & ENSBTAP00000002681 & 6.0 \\
\hline
\end{tabular}

The 25 most differentially expressed genes ( $>6$ fold; $p \leq 0.05$ ) between inner cell mass and trophectoderm are listed according to their relative expression. FC $=$ Fold change and positive values indicate higher expression in inner cell mass.

well as by qRT-PCR indicates that indeed the separation was specific and reproducible.

Several genes were represented on the array by multiple probes and in those cases we only used the expression data of the most 3'-located probe. Unfortunately, the Bos taurus genome is not completely annotated [39] and indeed approximately $5 \%$ of the probes representing genes differentially expressed between blastocyst and morula could not be identified. The other comparisons could be made with all probes linked to a known differentially expressed gene. For the Gene Ontology analysis genes need to be associated with a GO-term. Not all genes are associated with a GOterm and therefore $3.7 \%-5.3 \%$ of the genes could not be analysed in the AgriGO gene ontology analysis.

In vitro derived embryos were used as this enabled us to generate the numbers needed for RNA extraction. Particularly for the ICM and TE samples large numbers of embryos were needed to obtain sufficient amounts of RNA for hybridization (Additional file 2: Table S7).
Although a significant difference in gene expression between in vitro and in vivo derived embryos has been demonstrated [40] the birth of healthy animals from in vitro derived embryos indicates that the pathways for pluripotency are functional in these embryos. When gene expression was compared between different stages of in vivo derived bovine embryos most genes were found to be differentially expressed between early development (oocyte-4 cell stage) and later stages (8-cell stageblastocyst) [40]. Most likely these differences in gene expression are caused by embryonic genome activation around the 8-cell stage [40-42]. A larger number of genes $(\sim 1800)$ was expressed in in vivo derived oocytes compared with in vitro matured oocytes [40], indicating that in our study with in vitro derived embryos important genes may not have been detected. However, since in vitro derived embryos are commonly used for embryo transfer and give rise to healthy animals, it can be expected that genes important for pluripotency are 
Table 4 AgriGo parametric analysis of gene set enrichment (PAGE) analysis (inner cell mass versus trophectoderm)

\begin{tabular}{|c|c|c|c|c|c|}
\hline GO_acc & Ontology & Description & Genes \# & p-value & FDR \\
\hline GO:0016126 & $P$ & sterol biosynthetic process & 12 & $1.40 \mathrm{E}-11$ & $9.10 \mathrm{E}-09$ \\
\hline GO:0016125 & $P$ & sterol metabolic process & 20 & 2.00E-09 & $6.50 \mathrm{E}-07$ \\
\hline GO:0008202 & $P$ & steroid metabolic process & 28 & $1.00 \mathrm{E}-07$ & 1.70E-05 \\
\hline GO:0008203 & $P$ & cholesterol metabolic process & 18 & 8.90E-08 & $1.70 \mathrm{E}-05$ \\
\hline GO:0006694 & $P$ & steroid biosynthetic process & 20 & $2.00 \mathrm{E}-07$ & 2.60E-05 \\
\hline GO:0006629 & $P$ & lipid metabolic process & 62 & $6.40 \mathrm{E}-07$ & $6.10 \mathrm{E}-05$ \\
\hline GO:0008610 & $P$ & lipid biosynthetic process & 34 & $6.40 \mathrm{E}-07$ & $6.10 \mathrm{E}-05$ \\
\hline GO:0006720 & $P$ & isoprenoid metabolic process & 13 & 2.10E-05 & $1.70 \mathrm{E}-03$ \\
\hline GO:0006066 & $P$ & alcohol metabolic process & 54 & $1.50 \mathrm{E}-04$ & $1.10 \mathrm{E}-02$ \\
\hline GO:0044255 & $P$ & cellular lipid metabolic process & 39 & $2.20 \mathrm{E}-04$ & 1.40E-02 \\
\hline GO:0010038 & $P$ & response to metal ion & 14 & $3.70 \mathrm{E}-04$ & 2.20E-02 \\
\hline GO:0006721 & P & terpenoid metabolic process & 11 & $5.20 \mathrm{E}-04$ & 2.90E-02 \\
\hline GO:0023034 & $P$ & intracellular signaling pathway & 65 & $1.70 \mathrm{E}-03$ & 8.70E-02 \\
\hline GO:0018212 & P & peptidyl-tyrosine modification & 12 & 2.30E-03 & $9.40 \mathrm{E}-02$ \\
\hline GO:0018108 & $P$ & peptidyl-tyrosine phosphorylation & 12 & $2.30 \mathrm{E}-03$ & $9.40 \mathrm{E}-02$ \\
\hline GO:0007167 & P & enzyme linked receptor protein signaling pathway & 39 & $2.00 \mathrm{E}-03$ & $9.40 \mathrm{E}-02$ \\
\hline GO:0031090 & C & organelle membrane & 70 & 1.90E-04 & 7.40E-03 \\
\hline GO:0005773 & C & vacuole & 18 & $1.40 \mathrm{E}-04$ & 7.40E-03 \\
\hline GO:0042175 & C & nuclear envelope-endoplasmic reticulum network & 23 & $1.40 \mathrm{E}-04$ & 7.40E-03 \\
\hline GO:0005789 & C & endoplasmic reticulum membrane & 22 & 4.70E-04 & $1.00 \mathrm{E}-02$ \\
\hline GO:0005764 & C & lysosome & 17 & $5.10 \mathrm{E}-04$ & $1.00 \mathrm{E}-02$ \\
\hline GO:0000323 & C & lytic vacuole & 17 & $5.10 \mathrm{E}-04$ & $1.00 \mathrm{E}-02$ \\
\hline GO:0005768 & C & endosome & 23 & 1.40E-03 & $2.20 \mathrm{E}-02$ \\
\hline GO:0012505 & C & endomembrane system & 62 & $1.50 \mathrm{E}-03$ & 2.20E-02 \\
\hline GO:0044432 & C & endoplasmic reticulum part & 25 & $2.30 \mathrm{E}-03$ & 3.00E-02 \\
\hline
\end{tabular}

All genes differentially expressed between ICM and TE were assessed for their properties described by gene ontology (GO) terms in respect to their relative expression. This reveals 25 enriched GO-terms with a FDR $\leq 0.1$ in the GO domains Biological Process (P) and Cellular Component (C). Ranked according to Z-score. Bold descriptions indicate enrichment for inner cell mass. Regular descriptions indicate enrichment for trophectoderm. FDR = False Discovery Rate (Hochberg).

sufficiently expressed and the pathways for pluripotency are functional in in vitro derived embryos.

We started our analysis by comparing gene expression in blastocysts with that in morulae. This indicated that most differentially expressed genes are expressed at higher levels in the blastocyst but a GO-analysis revealed that most genes expressed at higher levels in morulae are involved in gene transcription. This might be a result of the embryonic genome activation initiated during the 8-16 cell stage in cattle embryos preceding the morula stage [40-42]. Next we tried to identify genes involved in pluripotency by comparing gene expressions in ICM and TE. Mouse and human ES cell pluripotency is regulated by NANOG, SOX2 and OCT4, and these factors enhance each other's transcription [43-45]. Indeed, their gene expression levels were found higher in the bovine ICM samples compared with TE. Remarkably, in the comparison of the ICM with the TE, expression of genes in the GO-category RNA splicing was specifically up- regulated in the ICM. This indicates a higher transcriptional activity in ICM cells than in TE cells. This is further reflected in the $>400$ genes up-regulated in ICM compared with TE. Using deep sequencing, Ozawa et al. examined genes differentially expressed between ICM and TE of day 8 in vitro derived embryos [32]. All of 8 ICM-characteristic genes that Ozawa et al. found were also up-regulated in our study, except for ZC3HAV1 and $I l 6 R$. Expression of Il6R was indeed significantly upregulated in the ICM but the difference was below the cut-off used (2-fold). These results confirm the specificity and reliability of the ICM isolation and microarray analysis. Compared with our results Ozawa et al. found more genes (870 versus 497 in our study) to be differentially expressed between ICM and TE, most likely because of the less stringent cut-off value used (1.5 versus 2.0 fold difference in our study) [32].

By enhancing the overall NANOG expression in the ICM we had anticipated that $S O X 2$ and POU5F1 expression 


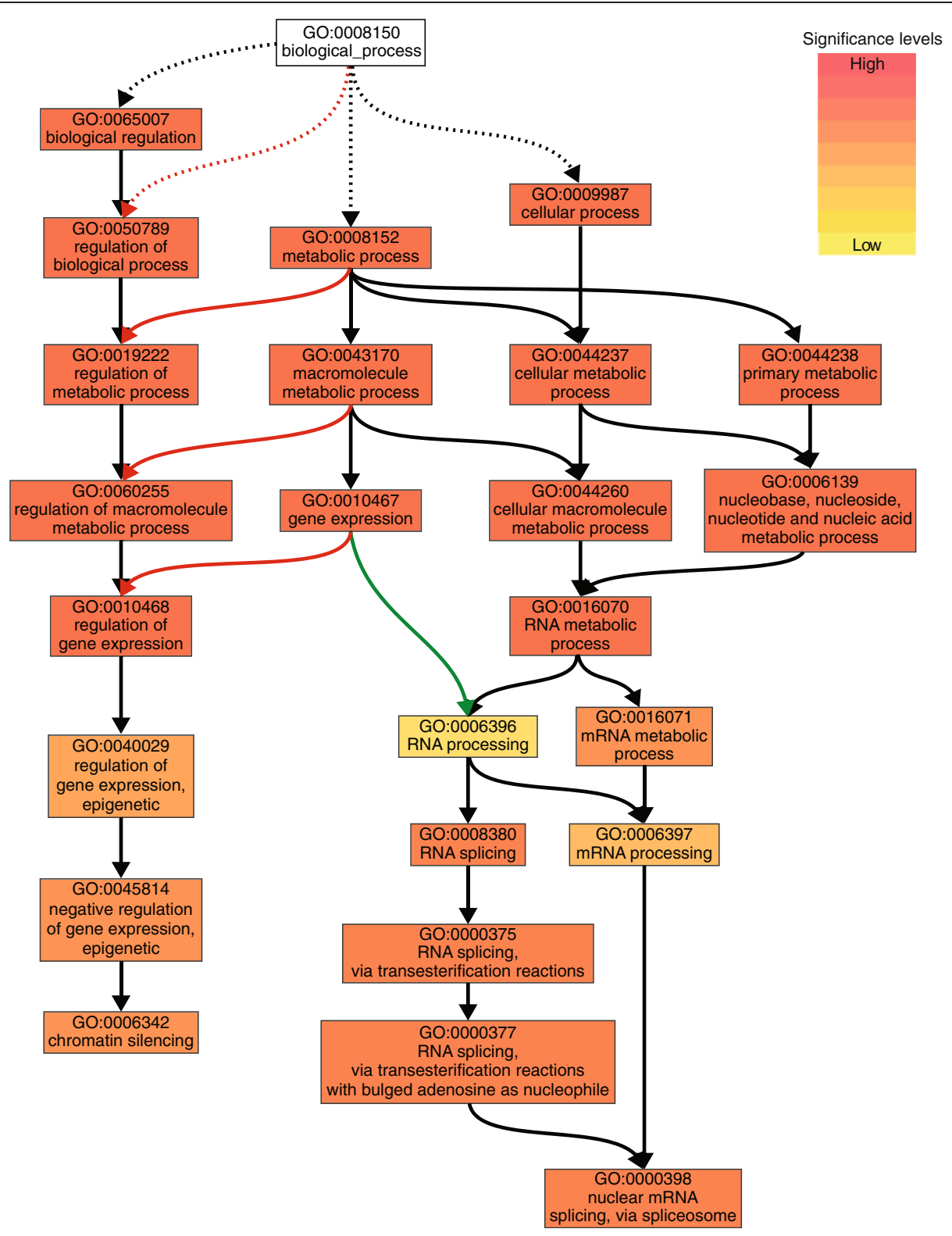

Figure 4 Biological processes in inner cell mass (partial). All genes expressed at higher levels in inner cell mass compared with trophectoderm were assessed for their enrichment (GO term analysis in AgriGO) in biological processes (GO:0008150). The hierarchical tree graph contains a highly enriched group of processes ending in chromatin silencing (GO:0006342) and nuclear mRNA splicing, via spliceosome (GO:0000398).

were similarly enhanced. Surprisingly however, in ICMs from embryos cultured in the presence of a MAPK inhibitor, gene expression levels of NANOG were up-regulated while those of POU5F1 and SOX2 remained relatively unchanged. These results suggest that in bovine cells NANOG by itself is not sufficient in maintaining the core pluripotency network.

An unexpected result was the expression of several interferon-coding genes in the ICM. Various reports have described exclusive IFNT expression in trophectoderm or TE derived cell lines [46-48]. We detected IFNT expression in the isolated ICMs at similar levels as in TE however and the expression in the ICM was down-regulated upon MAPK inhibition even to a greater extent than in TE. In ungulates, interferon tau (coded by IFNT) expression by $\mathrm{TE}$ is important for maternal pregnancy recognition [49]. In bovine day 7 blastocysts interferon tau has been detected at varying intensity in the $\mathrm{TE}$ and was concentrated at the border of the ICM and TE [48]. By dissecting the ICM, part if not all of the interferon tau-positive adjacent cells have been included in the ICM samples accounting for the observed IFNT expression in the ICM samples. Together with CDX2 predominantly expressed in TE cells and capable of 

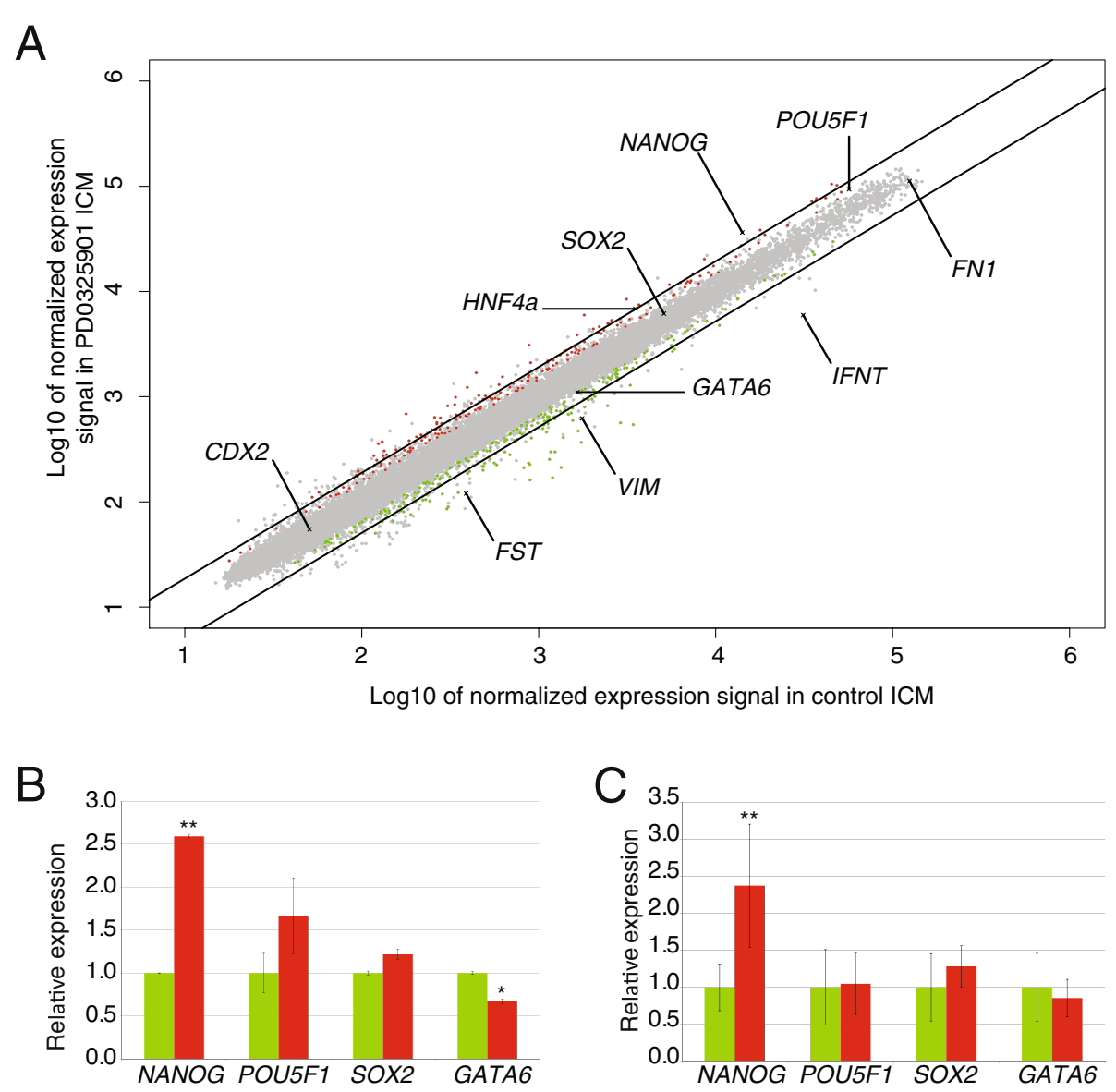

D

E
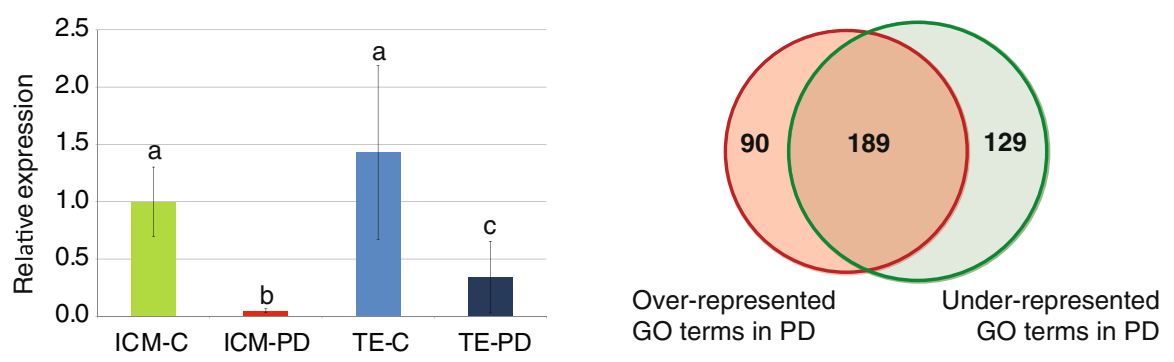

Figure 5 Expression in and GO-analysis of MAPK-inhibited and control inner cell mass. All probes representing genes (grey) were plotted for their expression levels (A). Black lines represent the 2-fold cut-off. Axes are Log10 transformed and depict the normalized expression signal in the indicated sample. Genes discussed in text (and analysed by qRT-PCR) are indicated. Genes with significant $(p \leq 0.05)$ higher expression levels in MAPK-inhibited and control inner cell masses are indicated with red and green dots, respectively. MAPK-inhibited ICM (red) gene expression of NANOG, POU5F1, SOX2 and GATA6 were determined by microarray $(\mathbf{B})$ and GRT-PCR (C) presented relative to gene expression in control ICM (green). Significant differences are indicated; ${ }^{*} p<0.05 ;{ }^{* *} p<0.005$. IFNT expression (D) was determined by qRT-PCR in control TE (light blue), PD0325901-treated TE (dark blue) and PD0325901-treated ICM (red) and presented relative to control ICM (green). Normalization was performed with the reference genes RPL15, SDHA and YWHAZ. Error bars indicate standard deviation and data bars with different letters are significantly different $(p<0.05)$. A Venn diagram (E) shows the numbers of overrepresented (red; total 279) and underrepresented (green; 318 in total) GO-terms in the MAPK-inhibited inner cell mass. 189 GO-terms are in common.

increasing IFNT transcription [46,50], this might explain the greater expression reduction found in ICM (20-fold) than in TE (4-fold). Nevertheless, our results and the previously reported location of interferon tau expression [48] do not exclude IFNT expression in the ICM even though its function in the ICM is unknown.

After exposure to PD0325901 expression of NANOG in the ICM was enhanced as compared to control ICMs. 
Table 5 AgriGo parametric analysis of gene set enrichment (PAGE) analysis (MAPK inhibited versus control)

\begin{tabular}{|c|c|c|c|c|c|}
\hline GO_acc & Ontology & Description & Genes \# & p-value & FDR \\
\hline GO:0005102 & $\mathrm{F}$ & receptor binding & 12 & 0.0016 & 0.027 \\
\hline GO:0005615 & C & extracellular space & 26 & 7.60E-05 & 0.003 \\
\hline GO:0044421 & C & extracellular region part & 28 & 0.00019 & 0.0036 \\
\hline GO:0005576 & C & extracellular region & 34 & 0.0033 & 0.043 \\
\hline GO:0043232 & C & intracellular non-membrane-bounded organelle & 18 & 0.0093 & 0.073 \\
\hline GO:0043228 & C & non-membrane-bounded organelle & 18 & 0.0093 & 0.073 \\
\hline
\end{tabular}

All genes differentially expressed between MAPK-inhibited and control ICMs were assessed for their properties described by gene ontology (GO) terms in respect to their relative expression. This revealed 6 enriched GO-terms with a FDR $\leq 0.1$ in the GO domains Molecular Function (F) and Cellular Component (C). Bold descriptions indicate enrichment in MAPK inhibited ICM. Regular descriptions indicate enrichment in control ICM.

In the mouse more than 3,000 genes have been identified containing NANOG binding sites [51]. Of the 42 genes identified to be differentially expressed in bovine ICMs and after MAPK inhibition, only five were homologous to murine genes containing NANOG binding sites. Of those genes only expression of NANOG was up-regulated after MAPK inhibition. Of the remaining four, CD8B, DUSP4, $J A M 2$ and SPRY4, the expression was enhanced in the ICM but their expression was down-regulated after MAPK inhibition. The role of the glycoprotein CD8B in early embryonic development, and more specifically in the ICM, is unclear. Its expression can be regulated however by MAPK signalling [52,53] possibly accounting for the observed down-regulation after PD0325901 treatment. DUSP4 is suggested to function in the negative feedback control of MAPK signalling specifically dephosphorylating ERK1/2 $[54,55]$. Also SPRY4 is known for its involvement in the MAPK pathway by interacting with GRB2 and GAP1 and as such inhibiting RAS activation [56] and antagonizing FGF activity [57]. Therefore, the down regulation of DUSP4 and SPRY4 expression by MAPK inhibition is most likely a direct result of the MAPK inhibition rather than result from the up-regulation of NANOG expression. JAM2 is expressed in both embryonic and adult stem cell lines [58] and its expression is enhanced in undifferentiated mouse ES cells compared to early stages of differentiation. Since mouse ES cells that genetically lack Jam 2 maintain pluripotency however, the function of JAM2 in stem cells remains unknown [59]. In mouse Sertoli cells inhibition of ERK activity did not affect Jam2 transcription [60], suggesting that the observed reduced JAM2 expression resulted from increased NANOG levels. Interestingly, JAM2 expression was also down-regulated after OCT4 had been exogenously introduced into human cells, suggesting that low levels of JAM2 induce or indicate differentiation [61]. In our bovine ICMs POU5F1 expression was however not significantly up-regulated after enhanced NANOG expression. Surprisingly, no other genes that had been identified as overlapping NANOG putative targets in mouse and human ES cells [51] appeared to be up- or down-regulated in bovine ICMs with enhanced NANOG expression.
Apart from the core pluripotency markers NANOG, SOX2 and OCT4, other transcription factors are reported to be involved in mouse or human pluripotency. Of all transcription factors differentially expressed between ICM and TE, OTX2 ranked third and was 7.2-fold higher expressed in ICM. In mouse ES cells OTX2 was reported to be required for the transition to a stable epiblast stem cell condition [62]. Recently, it was shown that OTX2 is one of the earliest transcription factors to be activated during exit from a naïve ground state in $\mathrm{mES}$ cells [63]. Although the MAPK pathway is important in cell differentiation [35] and therefore might influence OTX2 expression we did not detect a difference in OTX2 expression in the PD treated bovine ICMs. Together, these findings suggest that the ICMs under investigation were already in a "primed" state.

Transcription factors involved in the LIF or BMP pathway were also amongst the genes with up-regulated expression levels in the ICM. Although BMP4 was not differentially expressed, STAT3 (2.5-fold), ID3 (2.7-fold) and ID1 (6.7-fold) were expressed at higher levels in ICM than in TE. STAT3 is capable of suppressing mesoderm and endoderm commitment whereas ID genes suppress neuroectoderm commitment in mES cells. Fibronectin, with expression levels almost 4-fold higher in ICM, can induce Id expression and also NANOG is capable of activating STAT3 and inducing ID genes [64]. Up-regulated NANOG expression did however not induce STAT3 or ID expression in MAPK inhibited ICMs. Although the level of expression might not be high enough, the increased expression of STAT3, IDI and ID3 suggests that, although in a primed state, differentiation is not initiated yet in the bovine day 9 ICMs.

The transcription factor PRDM14 is implicated to act as a safeguard for maintaining pluripotency [65] and is uniquely expressed in mouse compacted morula, ICM, the early epiblast, primordial germ cells and ES cells [66-68]. Indeed, the expression of PRDM14 was found to be up-regulated in bovine morulae compared to blastocysts (2.4-fold; $\mathrm{p}=0.00097$ ) and ICM versus TE $(2.5$-fold; $\mathrm{p}=0.0015)$. It has been reported that in mouse ES cells PRDM14 attenuates FGFinduced differentiation [68]. We did however not observe a 
Table 6 List of genes differentially expressed in ICM versus TE and PD treated versus control ICMs

\begin{tabular}{|c|c|c|}
\hline Gene name & FC (ICMvsTE) & FC (PDvsControl) \\
\hline$\overline{\mathrm{ADH} 6}$ & 3.336 & -2.993 \\
\hline AHCYL2 & 5.379 & 2.068 \\
\hline C8A & 2.558 & 2.009 \\
\hline CD8B & 3.392 & -2.010 \\
\hline CKB & 3.660 & 2.062 \\
\hline CTSC & 3.064 & -2.517 \\
\hline CYP1A1 & 4.041 & -2.563 \\
\hline DHRS7 & 3.717 & 2.170 \\
\hline DUSP4 & 3.685 & -6.320 \\
\hline EMILIN2 & 5.463 & 2.697 \\
\hline FBLN1 & 2.215 & -2.160 \\
\hline FST & 2.468 & -3.235 \\
\hline GKN2 & 2.615 & -2.426 \\
\hline HAS2 & 7.117 & -2.237 \\
\hline JAM2 & 2.205 & -2.186 \\
\hline LOC100139049 & 2.661 & 2.276 \\
\hline LOC100139916 & 6.461 & -2.002 \\
\hline LOC100140174 & 3.096 & 2.880 \\
\hline LOC616039 & 7.437 & -2.203 \\
\hline MAP1B & 3.657 & 2.032 \\
\hline MEIS2 & 3.638 & -2.508 \\
\hline MFAP5 & 4.520 & -2.403 \\
\hline MYL9 & 2.257 & 3.305 \\
\hline NANOG & 13.215 & 2.575 \\
\hline NID1 & 6.536 & -2.072 \\
\hline P4HA3 & 3.279 & 2.083 \\
\hline PDGFRA & 6.583 & -2.116 \\
\hline PDYN & 6.053 & -2.398 \\
\hline PHLDA1 & 2.679 & -2.133 \\
\hline PRPH & -2.552 & 2.124 \\
\hline PRSS12 & 4.640 & 2.334 \\
\hline RSPO3 & 2.572 & -2.619 \\
\hline S100B & 3.875 & 3.516 \\
\hline SELP & 2.758 & 2.466 \\
\hline SERPINA5 & 5.908 & -7.057 \\
\hline SERPINH1 & 2.673 & -2.110 \\
\hline SLC1A3 & 3.230 & -2.249 \\
\hline SPRY4 & 4.314 & -2.065 \\
\hline TGM2 & 3.363 & -2.231 \\
\hline TIFA & 3.394 & -2.569 \\
\hline unknown & 2.868 & 2.076 \\
\hline VIM & 4.636 & -2.827 \\
\hline
\end{tabular}

Alphabetical ranking of differentially expressed genes $(p<0.05)$ in inner cell mass versus trophectoderm (ICMvsTE) and MAPK-inhibited versus control inner cell masses (PDvsControl). FC = Fold change in respect to ICM or PD.

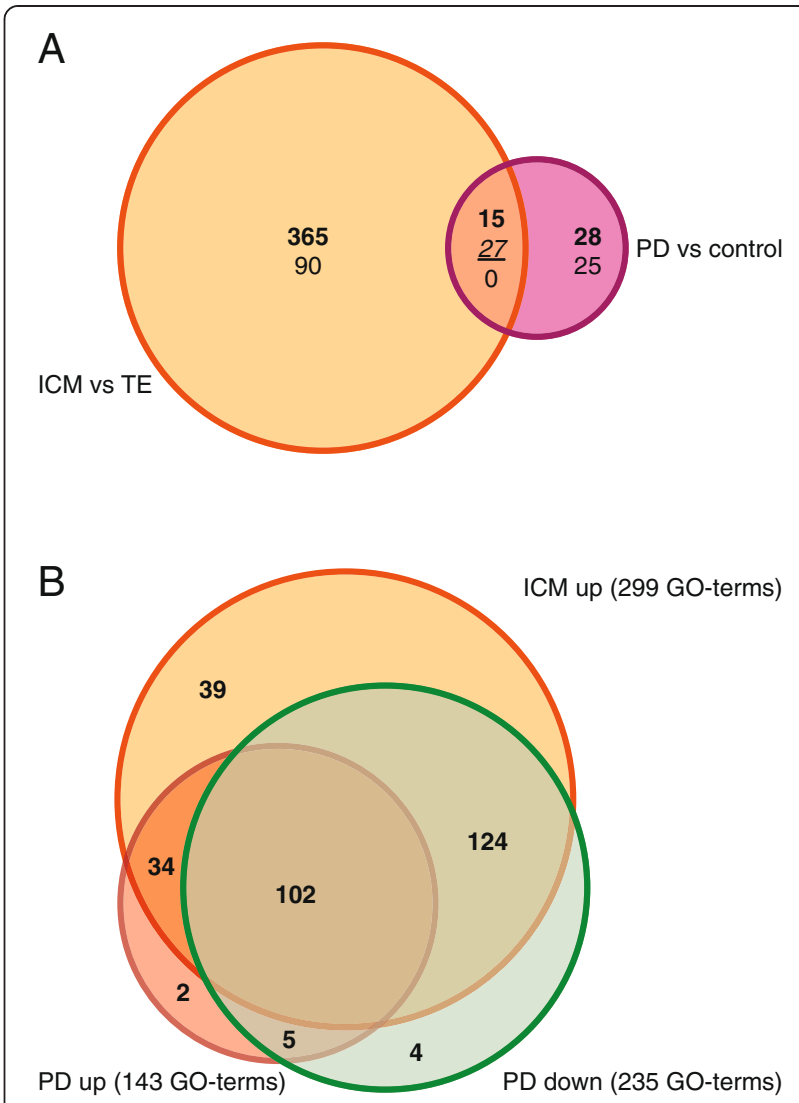

Figure 6 Gene expression and processes in the inner cell mass. (A) Of the 497 genes differentially expressed ( $\geq 2$-fold; $p \leq 0.05$ ) between ICM and TE (orange) several are up-regulated (bold) or down-regulated (regular) and 42 of these are also differentially expressed when inner cell masses treated with the MAPK-inhibitor PD0325901 (PD) are compared with control inner cell masses (magenta). This latter comparison retains 95 differentially expressed genes. Of the 42 shared genes 15 are up-regulated in both comparisons and 27 are contra-regulated (italics and underlined). (B) A gene ontology analysis with 41 ICM up-regulated genes (orange), 16 PD up-regulated (red) and 26 PD down-regulated (green) genes indicates several GO-terms of which 34 are enriched in both up-regulated gene analyses.

difference in levels of PRDM14 expression in MAPKinhibited ICMs (1.07 fold difference; $\mathrm{p}=0.87$ ), suggesting that the FGF- or MAPK-signalling pathways do not repress PRDM14 expression in bovine pluripotent cells. Expression of the ZIC gene family members ZIC2 and ZIC3 was also up-regulated in the ICM (4.3-fold and 2.2-fold, respectively). Zic2 and its orthologues are expressed in frog [69] and zebrafish [70], pregastrulation embryos and in mouse E0.5 and ICM of E4.5 embryos [71]. Zic3 is implicated to play an important role in maintaining pluripotency in mouse ES cells [72] and contains OCT4, NANOG and SOX2 binding sites [34,51]. Indeed, after increased NANOG expression by MAPK inhibition ZIC3 expression increases 1.5 fold $(\mathrm{p}=0.038)$ but ZIC2 expression decreased 2.2-fold $(\mathrm{p}>0.05)$. Other reported genes 
to safeguard pluripotency such as PARP1 and PARP7 [73] were expressed at higher levels in morula than in blastocyst (PARP7), did not show a differential expression between ICM and TE and were not differentially expressed after MAPK inhibition. All together, these findings indicate that, despite the increased ZIC3 and NANOG expression, MAPK inhibition by PD0325901 is insufficient to maintain a pluripotent state in bovine ICM cells.

\section{Conclusion}

We have identified whole genome expression profiles of different stages of bovine embryos and TE and the pluripotent ICM of blastocysts. In addition, the transcriptome of ICMs with enhanced NANOG expression after inhibition of MAPK activity was established. Unfortunately, these expression profiles did not lead to (new) pathways or indications how to maintain pluripotency and possibly generate genuine bovine ES cells. Furthermore, it became apparent that although MAPK inhibition increased NANOG and ZIC3 expression, this is insufficient to maintain pluripotency. Comparing transcription factor expression in the bovine ICMs used in the microarray with known expressions in mouse pluripotent cells indicates a "primed" or epiblast state. Therefore, the data presented in this paper can act as a starting point for further research on bovine pluripotency.

\section{Methods}

Bovine in vitro embryo culture and mechanical separation Bovine embryo culture was performed at $39^{\circ} \mathrm{C}$ in a humidified atmosphere with $5 \% \mathrm{CO}_{2}$, unless stated otherwise. Three to eight $\mathrm{mm}$ follicles of ovaries, obtained from a local slaughterhouse, were aspirated to retrieve COCs. Groups of 35-60 COCs were incubated for $23 \mathrm{hrs}$ in $500 \mu \mathrm{l}$ M199 (Life Technologies, Bleiswijk, The Netherlands) supplemented with $0.05 \mathrm{IU} / \mathrm{ml}$ recombinant hFSH (Organon, Oss, The Netherlands) and with 1\% (v/v) penicillin-streptomycin (Life Technologies). Fertilization was performed as described previously [74] with modifications as described [75]. In short, matured COCs were transferred to fertilization medium (Fert-TALP) supplemented with heparin at a final concentration of $10 \mu \mathrm{g} / \mathrm{ml}$ (Sigma-Aldrich, Zwijndrecht, The Netherlands), $20 \mu \mathrm{M}$ D-penicillamine (Sigma-Aldrich), $10 \mu \mathrm{M}$ hypotaurine (Sigma-Aldrich), and $1 \mu \mathrm{M}$ epinephrine (Sigma-Aldrich). Frozen-thawed sperm from a bull with proven fertility was centrifuged over a Percoll-gradient (GE Healthcare Europe GmbH, Eindhoven, The Netherlands) and added to the COCs at a final concentration of $1.0 \times 10^{6}$ spermatozoa $/ \mathrm{ml}$. Fertilization day was considered as day 0 . After incubation for $20 \mathrm{hrs}$ the COCs were denuded by vortexing for $3 \mathrm{~min}$ and the cumulus-free oocytes were placed in synthetic oviduct fluid (SOF) medium. The presumptive zygotes were incubated at $39^{\circ} \mathrm{C}$ in a humidified atmosphere with $7 \% \mathrm{O}_{2}$ and $5 \% \mathrm{CO}_{2}$. At day 5 either morulae were collected or embryos were transferred to fresh SOF medium, cultured to blastocyst stage embryos and collected on day 9. Embryos were cultured until day 9 of development as this resulted in a higher percentage of hatching and hatched blastocysts [30,76,77], which facilitated ICM from TE separation. To ensure good quality embryos only stage code 7-9 blastocysts with quality code 1 or 2 , according to the IETS manual, were collected $[78,79]$. To obtain ICMs containing a higher percentage of NANOG-expressing cells, SOF medium was supplemented with a final concentration of $0.5 \mu \mathrm{M}$ PD0325901 (Stemgent, Cambridge, MA, USA) at day 5. Embryo culture for control ICM samples was performed with equal concentrations of the solvent DMSO.

Blastocysts collected to obtain inner cell mass and trophectoderm were placed in wash buffer containing $6.67 \mathrm{mg} / \mathrm{ml} \mathrm{NaCl}$ (Merck, Schiphol-Rijk, The Netherlands), $0.24 \mathrm{mg} / \mathrm{ml} \mathrm{KCl}$ (Merck), $0.168 \mathrm{mg} / \mathrm{ml} \mathrm{NaHCO} 3$ (SigmaAldrich), $0.047 \mathrm{mg} / \mathrm{ml} \mathrm{NaH}_{2} \mathrm{PO}_{4}$ (Merck), $0.217 \%$ (v/v) of a $60 \%$ sodium lactate solution (Sigma-Aldrich), $2.38 \mathrm{mg} / \mathrm{ml}$ HEPES (Sigma-Aldrich), 0.2\% (v/v) phenolred (Sigma-Aldrich), $0.39 \mathrm{mg} / \mathrm{ml} \mathrm{CaCl} \cdot 2 \mathrm{H}_{2} \mathrm{O}$ (Sigma-Aldrich), $0.10 \mathrm{mg} /$ $\mathrm{ml} \mathrm{MgCl}_{2} \cdot 6 \mathrm{H}_{2} \mathrm{O}$ (Merck), $0.11 \mathrm{mg} / \mathrm{ml}$ sodium pyruvate, $100 \mathrm{U} / \mathrm{ml}$ Penicillin-Streptomycin (Life Technologies) and $6.0 \mathrm{mg} / \mathrm{ml}$ bovine serum albumin fraction 5 (MP Biomedicals, Santa Ana, CA, USA), set at an osmolality of 280 os$\mathrm{mol} / \mathrm{kg}$ and adjusted to $\mathrm{pH}$ 7.3.

Sharpened tungsten needles were used to manually separate the trophectoderm from the ICM. This procedure was performed in wash medium under a stereo microscope.

\section{RNA isolation}

Collected cells and embryos were harvested per tissue type or treatment and stored in $100 \mu \mathrm{l}$ extraction buffer (Life Technologies) at $-80^{\circ} \mathrm{C}$ until RNA isolation. RNA isolation and on column DNA digestion (Qiagen, Venlo, The Netherlands) was performed using the PicoPure RNA isolation kit (Life Technologies) according to the manufacturer's protocol. Total RNA quality and quantity assessment was performed by micro-electrophoresis on a Bioanalyzer 2100 using the RNA 6000 Pico LabChip kit (Agilent Technologies, Amstelveen, The Netherlands) according to manufacturer's instructions. RNA was stored at $-80^{\circ} \mathrm{C}$ until further use.

\section{Microarray gene expression analysis}

Selected total RNA samples were compared in a common reference experiment design using 12 dual channel microarrays (8 for the stage-/cell-specific microarray and 4 for the ERK-inhibition microarray) with each sample hybridized against an identical common reference total RNA sample consisting of a pool of blastocysts total RNA. Within 
each group of two microarrays for each stage/tissue type/ treatment, sample versus common reference hybridizations were performed in balanced dye-swap.

Microarrays used were bovine whole genome gene expression microarrays V2 (Agilent Technologies) representing 43,653 Bos taurus 60 -mer oligos in a $4 \times 44 \mathrm{~K}$ layout.

cDNA synthesis, cRNA double amplification, labelling, quantification, quality control and fragmentation were performed with an automated system (Caliper Life Sciences NV/SA, Teralfene, Belgium), starting with 10$20 \mathrm{ng}$ total RNA from each sample, all as previously described in detail $[80,81]$. Microarray hybridization and washing was with an HS4800PRO system with QuadChambers (Tecan, Mechelen, Belgie) using 700 ng, 1-2\% Cy5/Cy3 labelled cRNA per channel as described [80]. Slides were scanned on an Agilent G2565BA scanner at $100 \%$ laser power, $30 \%$ PMT. After automated data extraction using Imagene 8.0 (BioDiscovery, Hawthorne, CA, USA), Loess normalization was performed [82] on mean spot-intensities. Gene-specific dye bias was corrected by a within-set estimate [83]. Data were further analysed by MAANOVA [84], modelling sample, array and dye effects in a fixed effect analysis. P-values were determined by a permutation F2-test, in which residuals were shuffled 10000 times globally. Gene probes with $\mathrm{p}<0.05$ after false discovery rate determination (FDR by BenjaminiHochberg) were considered significantly changed. In cases of multiple probes per gene, the values from the most $3^{\prime}$ probe were used $[27,28]$. To determine differentially expressed genes a fold change cut-off of 2 fold was used. All microarray gene expression data have been deposited in NCBI's Gene Expression Omnibus [85] and are accessible through GEO Series accession number GSE63054 [86].

\section{Quantitative reverse transcription-PCR}

RNA was converted to cDNA using the iScript ${ }^{\text {tw }}$ cDNA Synthesis Kit (BioRad, Veenendaal, The Netherlands) according to manufacturer's instructions. Primers (Life Technologies; Additional file 2: Table S8) for specific Bos taurus mRNA templates [87] were designed using a Primer3 based platform [88]. Further in silico validation was performed by predicting PCR product folding structures using the Mfold web server [89-91]. For quantitative reverse transcription PCR (qRT-PCR) we used $\mathrm{iQ}^{\text {max }}$ SYBR $^{\circ}$ Green supermix on a MyiQ detection system (Biorad) in a $25 \mu \mathrm{l}$ reaction volume with a final primer concentration of $400 \mathrm{nM}$ according to manufacturer's instructions. To confirm specificity of primer pairs and establish melting temperatures $\left(\mathrm{T}_{\mathrm{m}}\right)$ a temperature gradient was performed ranging from $57.0^{\circ} \mathrm{C}-65.3^{\circ} \mathrm{C}$ using a 4 times dilution series of cDNA from blastocyst samples. Reactions started with a 5 min enzyme activation cycle at $95^{\circ} \mathrm{C}$ continued with 45 cycles in which the first step was $20 \mathrm{sec}$ denaturing at $95^{\circ} \mathrm{C}$, followed by $30 \mathrm{sec}$ at $\mathrm{T}_{\mathrm{m}}$ (Additional file 2: Table S8) for annealing and the third step for $30 \mathrm{sec}$ at $72^{\circ} \mathrm{C}$ for elongation. To generate a dissociation curve the reaction continued by increasing the temperature from $60^{\circ} \mathrm{C}$ to $98^{\circ} \mathrm{C}$ per $0.5^{\circ} \mathrm{C}$ for $15 \mathrm{sec}$ each step. For expression analysis of the individual samples the primer specific optimal $\mathrm{T}_{\mathrm{m}}$ was chosen (Additional file 2: Table S8) and the dissociation curve was generated with $1^{\circ} \mathrm{C}$ temperature increments per step until $98^{\circ} \mathrm{C}$.

\section{Immunostaining}

ICM, TE and blastocyst samples were collected and fixed in $4 \%$ paraformaldehyde (PFA) for $15 \mathrm{~min}$ and stored in $1 \%$ PFA at $4^{\circ} \mathrm{C}$ until further use. Samples were permeabilized in PBS $+10 \%$ FCS $+0.5 \%$ Triton X100 (Sigma Aldrich) for $30 \mathrm{~min}$. Next, a-specific binding was blocked by incubating the samples in PBS $+10 \%$ FCS + $0.1 \%$ Triton X100 (PBST) for 1 hour before overnight incubation with primary antibodies rabbit anti-GATA6 (Santa Cruz;sc-9055;1:100), mouse anti-CDX2 (Biogenex; CDX2-88; 1:200) or mouse anti-NANOG (eBiosciences; 14-5768-82;1:250) at $4^{\circ} \mathrm{C}$. Secondary antibody incubation for 1 hour with appropriate goat anti mouse Alexa647 or goat anti rabbit Alexa 488 dye (Invitrogen, Venlo, The Netherlands) and subsequent nuclear staining using DAPI (Sigma Aldrich) for $5 \mathrm{~min}$ preceded Vectashield (Brunschwig Chemie, Amsterdam, The Netherlands) mounting in Grace Bio-Labs SecureSeal ${ }^{\mathrm{m}}$ imaging spacer (Sigma-Aldrich). All incubations were performed at room temperature unless stated otherwise.

Fluorescent images were obtained using an inverted semi-automated confocal microscope (SPE-II - DMI4000; Leica, Son, The Netherlands) and further analysed with Fiji software [92].

\section{Additional files}

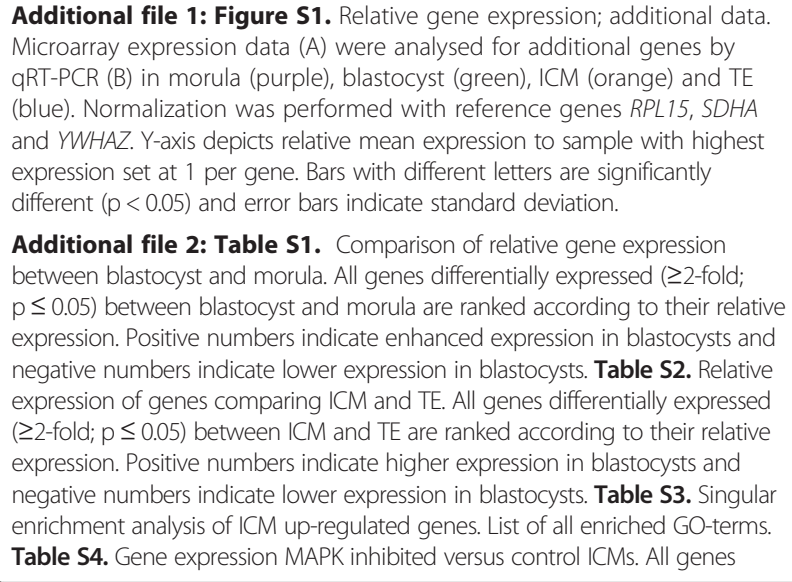

Additional file 1: Figure S1. Relative gene expression; additional data. Microarray expression data (A) were analysed for additional genes by qRT-PCR (B) in morula (purple), blastocyst (green), ICM (orange) and TE (blue). Normalization was performed with reference genes RPL15, SDHA and YWHAZ. Y-axis depicts relative mean expression to sample with highest expression set at 1 per gene. Bars with different letters are significantly different $(p<0.05)$ and error bars indicate standard deviation.

Additional file 2: Table S1. Comparison of relative gene expression between blastocyst and morula. All genes differentially expressed ( $\geq 2$-fold; $p \leq 0.05$ ) between blastocyst and morula are ranked according to their relative expression. Positive numbers indicate enhanced expression in blastocysts and negative numbers indicate lower expression in blastocysts. Table S2. Relative expression of genes comparing ICM and TE. All genes differentially expressed ( $\geq 2$-fold; $p \leq 0.05$ ) between ICM and TE are ranked according to their relative expression. Positive numbers indicate higher expression in blastocysts and negative numbers indicate lower expression in blastocysts. Table S3. Singular enrichment analysis of ICM up-regulated genes. List of all enriched GO-terms. Table S4. Gene expression MAPK inhibited versus control ICMs. All genes 
differentially expressed ( $\geq 2$-fold; $p \leq 0.05$ ) between MAPK inhibited versus control ICMs are listed according to their relative expression. Positive numbers indicate higher expression in MAPK-inhibited ICMs and negative numbers have higher expression in control ICMs. Table S5. Singular enrichment analysis of up-regulated genes in the PD treated or in the control ICMs. GO-terms enriched for genes with up-regulated expression (PD), with down-regulated expression (DMSO) or in both analyses (PD \&DMSO). Table S6. GOterms enriched with ICM up-regulated, PD up- or PD down-regulated genes. Singular enrichment analysis with ICM up-regulated, PD up- or PD down-regulated genes (minimum of two genes in a GO-term and a false discovery rate $\leq 0.1$ ). Table S7. Microarray sample composition. Numbers of embryos used for RNA extraction and subsequent microarray study are presented per sample. Note; Blastocyst sample 1 and 2 (B1 and B2) are identical to Blastocyst pool 1 and 2 (Bp1 and Bp2) respectively. Table S8. Primers used for qRT-PCR. Gener indicates a reference gene used for normalization.

Additional file 3: Figure S2. Hierarchical tree graph of GO-terms enriched with ICM vs. TE up-regulated genes in the biological process GO-domain. All 406 up-regulated genes in the ICM versus TE comparison were analysed for their enrichment in biological processes by a singular enrichment analysis.

Additional file 4: Figure S3. Relative gene expression in control and MAPK-inhibited inner cell mass; additional data. Microarray expression data (A) were confirmed by qRT-PCR (B) for 7 additional genes. MAPK-inhibited ICM (red) results are depicted relative to control ICM (green) expression. Normalization was performed with the reference genes RPL15, SDHA and YWHAZ. Error bars indicate standard deviation and significant differences are indicated by * $p<0.05 ; * * 0.005 ; * * * 0.0005$.

Additional file 5: Figure S4. Effect of MAPK inhibition.

Immunofluorescent staining for GATA6 (green) and NANOG (red) to determine protein distribution in control (upper panels) and MAPKinhibited (lower panels) embryos. DAPI was used for nuclear staining.

\section{Competing interests}

The authors declare that they have no competing interests.

\section{Authors' contributions}

BB participated in study design, carried out embryo culture, RNA isolation, microarray analysis, qRT-PCR, Immunostaining and co-wrote the manuscript. HTAT assisted in embryo culture and sample collection. MGK carried out microarray and performed statistical analysis. FMR performed statistical analysis. SIJ carried out aRT-PCR. KM performed statistical analysis. HH participated in the design and data analysis and co-wrote the manuscript. BAJR designed and coordinated the study, assisted in sample collection and co-wrote the manuscript. All authors read and approved the final manuscript.

\section{Acknowledgements}

The authors would like to thank Prof. Dr. Frank C.P. Holstege for suggestions on the micro-array analysis. Christine Oei is thanked for help in sample collection. Richard Wubbolts and Esther van 't Veld are thanked for their instructions and help with the confocal imaging. Kaveh Mashayekhi is funded by AniStem, Industry-Academia Partnerships and Pathways (IAPP), Project number: PIAPP-GA-2011-286264. Bas Brinkhof is funded by the Dutch Ministry of Economic Affairs.

\footnotetext{
Author details

'Department of Farm Animal Health, Faculty of Veterinary Medicine, Utrecht University, Yalelaan 104, Utrecht 3584 CM, The Netherlands. ${ }^{2}$ University Medical Center Utrecht, Molecular Cancer Research, PO Box 85060, Utrecht 3508 AB, The Netherlands. ${ }^{3}$ Department of Clinical Sciences of Companion Animals, Faculty of Veterinary Medicine, University Utrecht, Yalelaan 108, Utrecht 3584 CM, The Netherlands. ${ }^{4}$ BioTalentum Ltd, Aulich L u.26, Gödöllő 2100 , Hungary. ${ }^{5}$ Department of Infectious Diseases and Immunology, Faculty of Veterinary Medicine, Utrecht University, Yalelaan 1, Utrecht 3584 CL, The Netherlands.
}

Received: 26 February 2015 Accepted: 6 March 2015 Published online: 10 April 2015

\section{References}

1. Plusa B, Piliszek A, Frankenberg S, Artus J, Hadjantonakis AK. Distinct sequential cell behaviours direct primitive endoderm formation in the mouse blastocyst. Development. 2008;135(18):3081-91.

2. Chazaud C, Yamanaka Y, Pawson T, Rossant J. Early lineage segregation between epiblast and primitive endoderm in mouse blastocysts through the Grb2-MAPK pathway. Dev Cell. 2006;10(5):615-24.

3. Tanaka S, Kunath T, Hadjantonakis AK, Nagy A, Rossant J. Promotion to trophoblast stem cell proliferation by FGF4. Science. 1998;282(5396):2072-5.

4. Ralston A, Rossant J. Genetic regulation of stem cell origins in the mouse embryo. Clin Genet. 2005;68(2):106-12.

5. Strumpf D, Mao C, Yamanaka Y, Ralston A, Chawengsaksophak K, Beck F, et al. $C d \times 2$ is required for correct cell fate specification and differentiation of trophectoderm in the mouse blastocyst. Development. 2005;132(9):2093-102.

6. Wallingford MC, Angelo JR, Mager J. Morphogenetic analysis of periimplantation development. Dev Dyn. 2013;242(9):1110-20.

7. Zernicka-Goetz M, Morris SA, Bruce AW. Making a firm decision: Multifaceted regulation of cell fate in the early mouse embryo. Nat Rev Gen. 2009;10(7):467-77.

8. Kurosaka S, Eckardt S, McLaughlin KJ. Pluripotent lineage definition in bovine embryos by Oct4 transcript localization. Biol Reprod. 2004;71(5):1578-82.

9. Berg DK, Smith CS, Pearton DJ, Wells DN, Broadhurst R, Donnison M, et al. Trophectoderm lineage determination in cattle. Dev Cell. 2011;20(2):244-55.

10. Nichols J, Smith A. Naive and Primed Pluripotent States. Cell Stem Cell. 2009;4(6):487-92

11. Yamanaka Y, Lanner F, Rossant J. FGF signal-dependent segregation of primitive endoderm and epiblast in the mouse blastocyst. Development 2010;137(5):715-24.

12. Schrode N, Saiz N, Di Talia S, Hadjantonakis AK. GATA6 levels modulate primitive endoderm cell fate choice and timing in the mouse blastocyst. Dev Cell. 2014;29(4):454-67.

13. Kuijk EW, van Tol LTA, Van de Velde H, Wubbolts R, Welling M, Geijsen N, et al. The roles of FGF and MAP kinase signaling in the segregation of the epiblast and hypoblast cell lineages in bovine and human embryos. Development. 2012;139(5):871-82

14. Van Der Jeught M, O'Leary T, Ghimire S, Lierman S, Duggal G, Versieren K, et al. The combination of inhibitors of FGF/MEK/Erk and GSK3ß signaling increases the number of OCT3/4-and NANOG-positive cells in the human inner cell mass, but does not improve stem cell derivation. Stem Cells Dev. 2013;22(2):296-306.

15. Roode M, Blair K, Snell P, Elder K, Marchant S, Smith A, et al. Human hypoblast formation is not dependent on FGF signalling. Dev Biol. 2012;361 (2):358-63.

16. Evans MJ, Kaufman MH. Establishment in culture of pluripotential cells from mouse embryos. Nature. 1981;292(5819):154-6.

17. Martin GR. Isolation of a pluripotent cell line from early mouse embryos cultured in medium conditioned by teratocarcinoma stem cells. Proc Natl Acad Sci U S A. 1981;78(12):7634-8.

18. Thomson JA, Kalishman J, Golos TG, Durning M, Harris CP, Becker RA, et al. Isolation of a primate embryonic stem cell line. Proc Natl Acad Sci U S A. 1995;92(17):7844-8.

19. Thomson JA, Itskovitz-Eldor J, Shapiro SS, Waknitz MA, Swiergiel JJ, Marshall VS, et al. Embryonic stem cell lines derived from human blastocysts. Science. 1998;282(5391):1145-7.

20. Buehr M, Meek S, Blair K, Yang J, Ure J, Silva J, et al. Capture of authentic embryonic stem cells from rat blastocysts. Cell. 2008;135(7):1287-98.

21. Hackett JA, Surani MA. Regulatory principles of pluripotency: from the ground state up. Cell Stem Cell. 2014;15(4):416-30.

22. Telugu BPVL, Ezashi T, Roberts RM. The promise of stem cell research in pigs and other ungulate species. Stem Cell Rev Rep. 2010;6(1):31-41.

23. Tanaka TS, Kunath T, Kimber WL, Jaradat SA, Stagg CA, Usuda M, et al. Gene expression profiling of embryo-derived stem cells reveals candidate genes associated with pluripotency and lineage specificity. Genome Res. 2002;12(12):1921-8.

24. Hamatani T, Daikoku T, Wang H, Matsumoto H, Carter MG, Ko MSH, et al. Global gene expression analysis identifies molecular pathways distinguishing blastocyst dormancy and activation. Proc Natl Acad Sci U S A. 2004;101(28):10326-31.

25. Auer H, Lyianarachchi S, Newsom D, Klisovic M, Marcucci G, Kornacker K. Chipping away at the chip bias: RNA degradation in microarray analysis. Nat Genet. 2003;35(4):292-3. 
26. Eklund AC, Szallasi Z. Correction of technical bias in clinical microarray data improves concordance with known biological information. Genome Biol. 2008;9(2):R26.

27. Shi L. The MicroArray Quality Control (MAQC) project shows inter- and intraplatform reproducibility of gene expression measurements. Nat Biotech. 2006;24(9):1151-61.

28. Li Q, Birkbak N, Gyorffy B, Szallasi Z, Eklund A. Jetset: selecting the optimal microarray probe set to represent a gene. BMC Bioinformatics. 2011;12(1):474.

29. Xie D, Chen C, Ptaszek LM, Xiao S, Cao X, Fang F, et al. Rewirable gene regulatory networks in the preimplantation embryonic development of three mammalian species. Genome Res. 2010;20(6):804-15.

30. Madeja Z, Sosnowski J, Hryniewicz K, Warzych E, Pawlak P, Rozwadowska N, et al. Changes in sub-cellular localisation of trophoblast and inner cell mass specific transcription factors during bovine preimplantation development. BMC Dev Biol. 2013;13(1):32.

31. Khan DR, Dubé D, Gall L, Peynot N, Ruffini S, Laffont L, et al. Expression of Pluripotency Master Regulators during Two Key Developmental Transitions: EGA and Early Lineage Specification in the Bovine Embryo. PLoS One. 2012;7(3):e34110.

32. Ozawa M, Sakatani M, Yao J, Shanker S, Yu F, Yamashita R, et al. Global gene expression of the inner cell mass and trophectoderm of the bovine blastocyst. BMC Dev Biol. 2012;12(1):33.

33. Du Z, Zhou X, Ling Y, Zhang Z, Su Z. agriGO: a GO analysis toolkit for the agricultural community. Nucleic Acids Res. 2010;38 suppl 2:W64-70.

34. Boyer LA, Lee TI, Cole MF, Johnstone SE, Levine SS, Zucker JP, et al. Core transcriptional regulatory circuitry in human embryonic stem cells. Cell. 2005;122(6):947-56.

35. Ying Q, Wray J, Nichols J, Batlle-Morera L, Doble B, Woodgett J, et al. The ground state of embryonic stem cell self-renewal. Nature. 2008;453 (7194):519-23.

36. Veltmaat JM, Orelio CC, Ward-Van Oostwaard D, Van Rooijen MA, Mummery $\mathrm{CL}$, Defize LHK. Snail is an immediate early target gene of parathyroid hormone related peptide signaling in parietal endoderm formation. Int J Dev Biol. 2000;44(3):297-307.

37. Sumer H, Liu J, Malaver-Ortega LF, Lim ML, Khodadadi K, Verma PJ. NANOG is a key factor for induction of pluripotency in bovine adult fibroblasts. J Anim Sci. 2011;89(9):2708-16.

38. Nagatomo H, Kagawa S, Kishi Y, Takuma T, Sada A, Yamanaka K, et al. Transcriptional wiring for establishing cell lineage specification at the blastocyst stage in Cattle1. Biol Reprod. 2013;88(6):158.

39. Zimin AV, Delcher AL, Florea L, Kelley DR, Schatz MC, Puiu D, et al. A whole-genome assembly of the domestic cow, Bos taurus. Genome Biol. 2009;10(4):R42.

40. Kues WA, Sudheer S, Herrmann D, Carnwath JW, Havlicek V, Besenfelder $U$, et al. Genome-wide expression profiling reveals distinct clusters of transcriptional regulation during bovine preimplantation development in vivo. Proc Natl Acad Sci U S A. 2008;105(50):19768-73.

41. Sirard MA. Factors affecting oocyte and embryo transcriptomes. Reprod Domest Anim. 2012;47(Suppl4):148-55.

42. Graf A, Krebs S, Heininen-Brown M, Zakhartchenko V, Blum H, Wolf E. Genome activation in bovine embryos: Review of the literature and new insights from RNA sequencing experiments. Anim Reprod Sci. 2014;149 $(1-2): 46-58$

43. Loh KM, Lim B. A precarious balance: pluripotency factors as lineage specifiers. Cell Stem Cell. 2011;8(4):363-9.

44. Wang Z, Oron E, Nelson B, Razis S, Ivanova N. Distinct Lineage Specification Roles for NANOG, OCT4, and SOX2 in Human Embryonic Stem Cells. Cell Stem Cell. 2012;10(4):440-54.

45. Jaenisch R, Young R. Stem Cells, the Molecular Circuitry of Pluripotency and Nuclear Reprogramming. Cell. 2008;132(4):567-82.

46. Sakurai T, Sakamoto A, Muroi Y, Bai H, Nagaoka K, Tamura K, et al. Induction of endogenous interferon tau gene transcription by CDX2 and high acetylation in bovine nontrophoblast cells. Biol Reprod. 2009;80(6):1223-31.

47. Ezashi T, Ghosh D, Roberts RM. Repression of Ets-2-induced transactivation of the tau interferon promoter by Oct-4. Mol Cell Biol. 2001;21(23):7883-91.

48. Johnson KM, Alvarez X, Borkhsenious ON, Kubisch HM. Nuclear and cytoplasmic localization of interferon-t in in vitro-produced bovine blastocysts. Reprod Nutr Dev. 2006;46(1):97-104.

49. Roberts RM. Interferon-tau, a Type 1 interferon involved in maternal recognition of pregnancy. Cytokine Growth Factor Rev. 2007;18(5-6):403-8.
50. Imakawa K, Kim MS, Matsuda-Minehata F, Ishida S, lizuka M, Suzuki M, et al. Regulation of the ovine interferon-tau gene by a blastocyst-specific transcription factor, Cdx2. Mol Reprod Dev. 2006;73(5):559-67.

51. Loh YH, Wu Q, Chew JL, Vega VB, Zhang W, Chen X, et al. The Oct4 and Nanog transcription network regulates pluripotency in mouse embryonic stem cells. Nat Genet. 2006;38(4):431-40.

52. D'Souza WN, Chang CF, Fischer AM, Li M, Hedrick SM. The Erk2 MAPK regulates CD8 T cell proliferation and survival. J Immunol. 2008;181(11):7617-29.

53. Wilkinson B, Kaye J. Requirement for sustained MAPK signaling in both CD4 and CD8 lineage commitment: A threshold model. Cell Immunol. 2001;211(2):86-95.

54. Kondoh K, Nishida E. Regulation of MAP kinases by MAP kinase phosphatases. Biochim Biophys Acta Mol Cell Res. 2007;1773(8):1227-37.

55. Chu Y, Solski PA, Khosravi-Far R, Der CJ, Kelly K. The mitogen-activated protein kinase phosphatases PAC1, MKP-1, and MKP-2 have unique substrate specificities and reduced activity in vivo toward the ERK2 sevenmaker mutation. J Biol Chem. 1996;271(11):6497-501.

56. Casci T, Vinós J, Freeman M. Sprouty, an intracellular inhibitor of Ras signaling Cell. 1999;96(5):655-65.

57. Fürthauer M, Reifers F, Brand M, Thisse B, Thisse C. Sprouty4 acts in vivo as a feedback-induced antagonist of FGF signaling in zebrafish. Development. 2001;128(12):2175-86.

58. Ivanova NB, Dimos JT, Schaniel C, Hackney JA, Moore KA, Lemischka IR. A stem cell molecular signature. Science. 2002;298(5593):601-4.

59. Sakaguchi T, Nishimoto M, Miyagi S, Iwama A, Morita Y, Iwamori N, et al. Putative "stemness" gene Jam-B is not required for maintenance of stem cell state in embryonic, neural, or hematopoietic stem cells. Mol Cell Biol. 2006;26(17):6557-70.

60. Wang Y, Lui WY. Opposite effects of interleukin-1a and transforming growth factor- 32 induce stage-specific regulation of junctional adhesion molecule-B gene in sertoli cells. Endocrinology. 2009;150(5):2404-12.

61. Kim JH, Jee MK, Lee SY, Han TH, Kim BSBS, Kang KS, et al. Regulation of adipose tissue stromal cells behaviors by endogenic Oct4 expression control. PLoS One. 2009;4(9):e7166.

62. Acampora D, Di Giovannantonio LG, Simeone A. Otx2 is an intrinsic determinant of the embryonic stem cell state and is required for transition to a stable epiblast stem cell condition. Development. 2013;140(1):43-55.

63. Yang SH, Kalkan T, Morissroe C, Marks H, Stunnenberg H, Smith A, et al. Otx2 and Oct4 Drive Early Enhancer Activation during Embryonic Stem Cell Transition from Naive Pluripotency. Cell Rep. 2014;7(6):1968-81.

64. Ying QL, Nichols J, Chambers I, Smith A. BMP induction of Id proteins suppresses differentiation and sustains embryonic stem cell self-renewal in collaboration with STAT3. Cell. 2003;115(3):281-92.

65. Ma Z, Swigut T, Valouev A, Rada-Iglesias A, Wysocka J. Sequence-specific regulator Prdm14 safeguards mouse ESCs from entering extraembryonic endoderm fates. Nat Struct Mol Biol. 2011;18(2):120-8.

66. Yamaji M, Seki Y, Kurimoto K, Yabuta Y, Yuasa M, Shigeta $M$, et al. Critical function of Prdm14 for the establishment of the germ cell lineage in mice. Nat Genet. 2008;40(8):1016-22.

67. Kurimoto K, Yabuta Y, Ohinata Y, Ono Y, Uno KD, Yamada RG, et al. An improved single-cell cDNA amplification method for efficient high-density oligonucleotide microarray analysis. Nucleic Acids Res. 2006;34(5):e42.

68. Grabole N, Tischler J, Hackett JA, Kim S, Tang F, Leitch HG, et al. Prdm14 promotes germline fate and naive pluripotency by repressing FGF signalling and DNA methylation. EMBO Rep. 2013;14(7):629-37.

69. Kuo JS, Patel M, Gamse J, Merzdorf C, Liu X, Apekin V, et al. opl: A zinc finger protein that regulates neural determination and patterning in Xenopus. Development. 1998;125(15):2867-82.

70. Grinblat $Y$, Sive H. zic gene expression marks anteroposterior pattern in the presumptive neurectoderm of the zebrafish gastrula. Dev Dyn. 2001;222 (4):688-93.

71. Brown L, Brown S. Zic2 is expressed in pluripotent cells in the blastocyst and adult brain expression overlaps with makers of neurogenesis. Gene Expr Patterns. 2009;9(1):43-9.

72. Lim LS, Loh YH, Zhang W, Li Y, Chen X, Wang Y, et al. Zic3 is required for maintenance of pluripotency in embryonic stem cells. Mol Biol Cell. 2007;18 (4):1348-58

73. Roper SJ, Chrysanthou S, Senner CE, Sienerth A, Gnan S, Murray A, et al. ADP-ribosyltransferases Parp1 and Parp7 safeguard pluripotency of ES cells. Nucleic Acids Res. 2014;42(14):8914-27.

74. Parrish JJ, Susko-Parrish J, Winer MA, First NL. Capacitation of bovine sperm by heparin. Biol Reprod. 1988;38(5):1171-80. 
75. Izadyar F, Colenbrander B, Bevers MM. In vitro maturation of bovine oocytes in the presence of growth hormone accelerates nuclear maturation and promotes subsequent embryonic development. Mol Reprod Dev. 1996:45(3):372-7.

76. Rizos D, Gutiérrez-Adán A, Pérez-Garnelo S, De la Fuente J, Boland MP, Lonergan P. Bovine embryo culture in the presence or absence of serum: Implications for blastocyst development, cryotolerance, and messenger RNA expression. Biol Reprod. 2003;68(1):236-43.

77. Nicacio AC, Simõs R, De Paula-Lopes FF, De Barros FRO, Peres MA, Assumpção MEOD, et al. Effects of different cryopreservation methods on post-thaw culture conditions of in vitro produced bovine embryos. Zygote. 2012;20(2):117-22.

78. Stringfellow DA, Givens MD. A procedural guide and general information for the use of embryo transfer technology emphasizing sanitary procedures. In: Manual of the International Embryo Transfer Society, editor. International Embryo Transfer Manual. 4th ed. Savoy, IL, USA: IETS Publish; 2009. p. 151.

79. Bó GA, Mapletoft RJ. Evaluation and classification of bovine embryos. Anim Reprod. 2013;10(3):344-8.

80. van Wageningen S, Kemmeren P, Lijnzaad P, Margaritis T, Benschop JJ, de Castro IJ, et al. Functional overlap and regulatory links shape genetic interactions between signaling pathways. Cell. 2010;143(6):991-1004

81. Roepman $P$, de Koning E, van Leenen D, de Weger R, Kummer JA, Slootweg $P$, et al. Dissection of a metastatic gene expression signature into distinct components. Genome Biol. 2006;7(12):1-12.

82. Yang YH, Dudoit S, Luu P, Lin DM, Peng V, Ngai J, et al. Normalization for cDNA microarray data: a robust composite method addressing single and multiple slide systematic variation. Nucleic Acids Res. 2002;30(4):e15.

83. Margaritis T, Lijnzaad $\mathrm{P}$, van Leenen D, Bouwmeester D, Kemmeren $\mathrm{P}$ van Hooff SR, et al. Adaptable gene-specific dye bias correction for twochannel DNA microarrays. Mol Syst Biol. 2009;5(1):266.

84. Wu H, Kerr MK, Cui X, Churchill G. MAANOVA: A Software Package for the Analysis of Spotted cDNA Microarray Experiments. In: Parmigiani G, Garrett E, Irizarry R, Zeger S, editors. The analysis of gene expression data: methods and software. New York: Springer; 2003. p. 313-41.

85. Edgar R, Domrachev M, Lash AE. Gene Expression Omnibus: NCBI gene expression and hybridization array data repository. Nucleic Acids Res. 2002:30(1):207-10.

86. GSE63054 is the reference Series for your publication [http://www.ncbi.nlm. nih.gov/geo/query/acc.cgi?acc=GSE63054]

87. Genbank [http://www.ncbi.nlm.nih.gov/nucleotide/]

88. Primer-Blast [http://www.ncbi.nlm.nih.gov/tools/primer-blast/]

89. SantaLucia J. A unified view of polymer, dumbell, and oligonucleotide DNA nearest-neighbor thermodynamics. Proc Natl Acad Sci U S A. 1998:95(4):1460-5.

90. Zuker M. Mfold web server for nucleic acid folding and hybridization prediction. Nucleic Acids Res. 2003;31(13):3406-15.

91. Mfold [http://mfold.rit.albany.edu/?q=mfold/DNA-Folding-Form]

92. Schindelin J, Arganda-Carreras I, Frise E, Kaynig V, Longair M, Pietzsch T, et al. Fiji: An open-source platform for biological-image analysis. Nat Methods. 2012;9(7):676-82.

\section{Submit your next manuscript to BioMed Central and take full advantage of:}

- Convenient online submission

- Thorough peer review

- No space constraints or color figure charges

- Immediate publication on acceptance

- Inclusion in PubMed, CAS, Scopus and Google Scholar

- Research which is freely available for redistribution

Submit your manuscript at www.biomedcentral.com/submit 